\title{
A Livelihood and Farming System approach for effective conservation policies in Protected Areas of Developing Countries: The case study of the Niassa National Reserve in Mozambique
}

\author{
Aires Afonso Mbanze ${ }^{\mathrm{a}, \mathrm{b}, \mathrm{c}, *}$, Carina Viera da Silva ${ }^{\mathrm{b}, \mathrm{d}}$, Natasha Sofia Ribeiro ${ }^{\mathrm{d}, \mathrm{e}}$, João F. Silva ${ }^{\mathrm{f}, * *}$, \\ José Lima Santos ${ }^{c}$ \\ ${ }^{\text {a }}$ Faculty of Agrarian Sciences, Universidade Lúrio, Department of Environment and Nature Conservation, Unango Campus, Sanga District, Niassa Province, Mozambique \\ ${ }^{\mathrm{b}}$ Nova School of Business and Economics, Universidade Nova de Lisboa, Campus de Carcavelos, Rua da Holanda 1, P.O. Box. 2775-405, Lisbon, Portugal \\ ${ }^{\mathrm{c}}$ Centre for Forest Studies (CEF), Instituto Superior de Agronomia (ISA), Universidade de Lisboa, Tapada da Ajuda, P.O. Box, 1349-017 Lisbon, Portugal \\ ${ }^{\mathrm{d}}$ MARE - Marine and Environmental Sciences Centre, Faculdade de Ciências, Universidade de Lisboa, Av. Nossa Sr ${ }^{a}$ do Cabo 939, 2750-374 Cascais, Portugal \\ ${ }^{\mathrm{e}}$ Eduardo Mondlane University, Faculty of Agronomy and Forest Engineering, Av. J. Nyerere 3453/Campus Universitário Principal, Maputo, Mozambique \\ ${ }^{\mathrm{f}}$ LEAF, Linking Landscape, Environment, Agriculture and Food Research Center, Instituto Superior de Agronomia, University of Lisbon, Lisbon, 1349-017, Portugal
}

\section{A R T I C L E I N F O}

\section{Keywords:}

Biophysical and socio-economic drivers

Conservation policies

Crop raiding

Farming and livelihoodsystems and Protected

Areas

\begin{abstract}
A B S T R A C T
Effective conservation requires that conservation policies and management decisions first target local actors who are dependent on natural resource use in Protected Areas (PA) of Developing Countries (DC). In rural areas of DCs, these actors are mainly farmers who also rely on off-farm activities such as harvest of Non-Timber Forest Products (NTFPs) to complement their livelihoods. Here, we propose a novel approach to support the development of policy interventions aimed at achieving conservation goals through the sustainable development of local people in PAs of DCs. The approach consists in identifying the main Livelihood and Farming Systems (LFS) and select those that are more conservation-friendly, and that may contribute to solve conservation and development problems such as Human-wildlife conflict. Identifying the existing LFS can also help in searching for conservation-relevant improvements that can contribute to local people wellbeing, considering the existing FS as the starting point for a sustainable development strategy in PAs of DC. Data from the Niassa National Reserve (NNR), the largest PA in Mozambique, were used to develop this LFS approach. Measures of effort applied in harvesting NTFPs and in managing agricultural inputs and outputs were collected from 329 households through a structured survey. Cluster analysis was performed to identify and characterise the main LFS in the NNR. Based on the cluster results, we have identified four livelihood systems (LS): gatherers, hunters, farmers and employees; four farming systems (FS): specialized in maize, rice and sorghum, and a mixed FS. A Multinomial Logistic Model was also applied to understand the drivers of LFS choice. Livelihood systems were mainly driven by householdlevel socio-economic factors, while FS were driven by village-level biophysical conditions. Households who were employed and had diversified farming and off-farm activities were better off and more resilient to climate change and crop-raiding animals. Intensification appears to occur gradually but has found to be limited by rainfall availability. Based on our findings, we propose that conservation experts and policy-makers should use a LFS approach to re-frame the conservation narrative in PAs of DCs and promote the existing practices that can better protect biodiversity while improving livelihood and welfare of local people.
\end{abstract}

\section{Introduction}

Efforts to reduce environmental degradation are underway worldwide (Peterman et al., 2013). However, those efforts are even more challenging in Developing Countries (DCs) (Brister, 2016; Cooney et al., 2017; Struhsaker et al., 2005), where conservation policies and

\footnotetext{
* Corresponding author at: Department of Environment and Nature Conservation, Faculty of Agricultural Science (FCA), Universidade Lúrio, Sanga University Campus, Niassa Province, Mozambique.

$* *$ Corresponding author

E-mail addresses: airesmbanze@unilurio.ac.mz (A.A. Mbanze), carina.silva@novasbe.pt (C. Viera da Silva).
} 
strategies are frequently focused on reducing biodiversity loss, especially the loss of endangered species (Gaillard et al., 2019; Galvin et al., 2006), rather than on human behaviours that are the core drivers of environmental and ecosystem services degradation (Jew et al., 2019).

In uninhabited Protected Areas (PAs), management efforts toward reducing biodiversity loss have generated the expected results (Beale et al., 2013), unlike in many inhabited PAs, where the local people are the core agents of ecosystem services use (Baral and Heinen, 2007; Bluwstein and Lund, 2016). In these areas, a significant share of the land is managed by small farmers, foresters, hunters, fishers and gatherers of provisioning services (Beale et al., 2013). Thus, management decisions are primarily driven by markets, policies, biophysical and socioeconomic conditions, rather than by the pursuit of conservation goals (Kramer et al., 2009). For conservation strategies and intervention to be more effective, PA managers and policy-makers need to fundamentally shift their focus from directly managing ecosystems to managing the behaviour of economic agents, so that they can choose the available options that deliver both better conservation results and improved human well-being. This requires acquiring knowledge about: (1) the management options available in the area; (2) the key drivers that lead agents to choose between different options (Alemayehu et al., 2018); and (3) those options that can be selected to promote conservation. This knowledge will enable conservation authorities and PA managers to design conservation policies and strategies that act on the drivers of people's choices and thereby promote those options that have the highest conservation value.

A promising approach to identifying existing management options available to local economic agents is to identify the farming systems (FS) occurring within the PA (Ribeiro et al., 2014). For this purpose, a FS is seen as a group of farms that are similar regarding the way they merge inputs (land, labour, and means of production, e.g. fertilizers), with a similar mix of cropping and livestock activities (sub-systems), to produce a similar bundle of agricultural outputs (Dixon, 2019; Ferraton and Touzard, 2009; Reboul, 2009). A FS approach can be applied to specific farm-level data on inputs and outputs to define a local typology of FS and to select the best available options for local land managers.

Moreover, alongside farming, there are other relevant options (e.g. hunting, fishing, or gathering) to generate income and subsistence (Dixon, 2019). Those alternatives are sometimes even more important than farming, for ecosystem management and conservation, in the case in many PAs of DCs (Dehghani Pour et al., 2017). Thus, FS can be seen as a part (or subsystem) of a broader livelihood system (LS) that comprises all possible income-generating activities (Alemayehu et al., 2018; Dixon, 2019). In this case, we should identify both a broader typology of livelihood systems, for all households, and a more detailed typology of FS, for those who are farmers. These two typologies would provide us with a richer picture of the most dominant management options available for local economic agents within PAs.

Defining existing Livelihood and Farming Systems (LFS) can provide us with a system-based approach that better captures available options for policy proposals rather than defining individual practices because households practice a specific LFS to achieve a common goal. Management decisions based on individual practices are then best understood as a system of strongly inter-related practices that respond to biophysical constraints (Staal et al., 2002) and to environment and socioeconomic opportunities (Dixon et al., 2001; Maru et al., 2018; van de Steeg et al., 2010). For example, if endemic diseases (e.g. animal trypanosomiasis) or potential predation of cattle hinder livestock raising, local people will be more dependent on bushmeat to fulfil their protein needs. Likewise, if crop raiding by wild fauna prevents households from actively investing in crops, they would be expected to rationally shift their effort either to less susceptible crops or to other off-farming practices such as the gathering of NTFPs. The prevalence of endemic diseases and livestock raiding have already been reported in the Niassa National Reserve (NCP, 2017) and in other PAs of DCs (Auty et al., 2016; Kuiper et al., 2015), imposing considerable threat to livestock raising. Furthermore, other authors have reported changes in the type of crop or a shift to other off-farming practices as a consequence of crop raiding in PAs of DCs (Dickman, 2010; Lemessa et al., 2013). Second, choices among individual practices are interdependent on one another. For example: using a genetically improved and more productive variety of rice would entail using more intensive FS. Third, the fact that practices are interdependent within the LFS (Alemayehu et al., 2018) may allow us to identify farm-level management details with important conservation impacts (e. g. harvest dates or use of pesticides). Fourth, the fact that these practices exist implies that the LS and FS are clearly available management options for local households, that one needs to take in consideration when drawing conservation policies/strategies. Thus, enhancing the existing practices will probable be much easier than challenging farmers to abruptly change their longstanding habits.

Four aspects of wildlife conservation and management in PAs of DCs are highlighted in this paper: First, PAs of DCs are keystones for biodiversity conservation worldwide (Macdonald et al., 2012; Saura et al., 2017; WWF, 2012) as they are crucial for sustainable development strategies, supporting the achievement of the Sustainable Development Goals (Snyman and Bricker, 2016); Second, in the richest biodiversity hotspots, significant numbers of people are dependent on the ecosystem services of those areas (Dewees et al., 2010; Jew et al., 2016) and most of their daily practices contribute to biodiversity loss (Dikgang and Muchapondwa, 2012; Naidu and Kumar, 2016). For instance, the expansion of farmland has been identified to be the main driver of terrestrial biodiversity loss (Meyfroidt and Lambin, 2008), particularly in tropical forests of DCs (Galvin et al., 2006; Twongyirwe et al., 2018). A possible solution would be to intensify agricultural production to avoid farmland expansion (the land-sparing option) ${ }^{1}$ (Hockings and McLennan, 2012). However, this strategy may be blocked by biophysical constraints (e.g. low rainfall, nutrient-poor soils) (Staal et al., 2002) and lack of appropriate technologies; furthermore, even intensification itself may be a driver of biodiversity loss. The third aspect is that farmers in PAs of DCs are vulnerable to crop raiding, predation of livestock and endemic diseases affecting livestock, which can be major drivers in the choice among LFS (Seiler and Robbins, 2016). Human-wildlife conflicts (HWC), may induce local people to become involved in illegal hunting of the wild animals that cause crop damages (Moreto, 2019; Rogan et al., 2017) or to cooperate with poachers coming from outside the PA (Dickman and Hazzah, 2015; Mbanze et al., 2019b; Shepherd and Magnus, 2004). These deviations from intended objectives usually occur when PA authorities do not deliver a solution or sufficient levels of benefit to offset uneconomical levels of agricultural output loss from crop-raiding (Moreto, 2019). The last aspect, but not the least, is that local economic agents in PAs of DCs are among the poorest people on Earth (Bieber-Klemm et al., 2006; Snyman and Bricker, 2016), and acute food insecurity problems persist within these PAs (den Braber et al., 2018; NCP, 2017). This means that no conservation policy or strategy will work without explicitly addressing needs for development and food security, and health challenges.

FS and LS analysis have been used to frame these problems (Dixon et al., 2001). Particular solutions have been put forward, such as diversification of FS into cash crops, intensification of FS (Alemayehu et al., 2018; Seiler and Robbins, 2016), and diversification of LS to off-farm activities (Alemayehu et al., 2018; Dickman, 2010; Smith et al., 2017) and non-gathering activities (Lindsey et al., 2017), such as the promotion of eco-tourism (Snyman and Bricker, 2016) or public employment in PA-related activities.

\footnotetext{
${ }^{1}$ Following the ongoing debate (see, for instance, Fischer et al., 2014 and Kremen, 2015), we also acknowledge the complexity surrounding the land sparing/land sharing dichotomy, in the sense that neither can be considered a full solution. Only a value trade-off amongst possible efficient allocation appears to be more or less favorable, depending on specific context and the desired outcome (Game et al., 2014).
} 

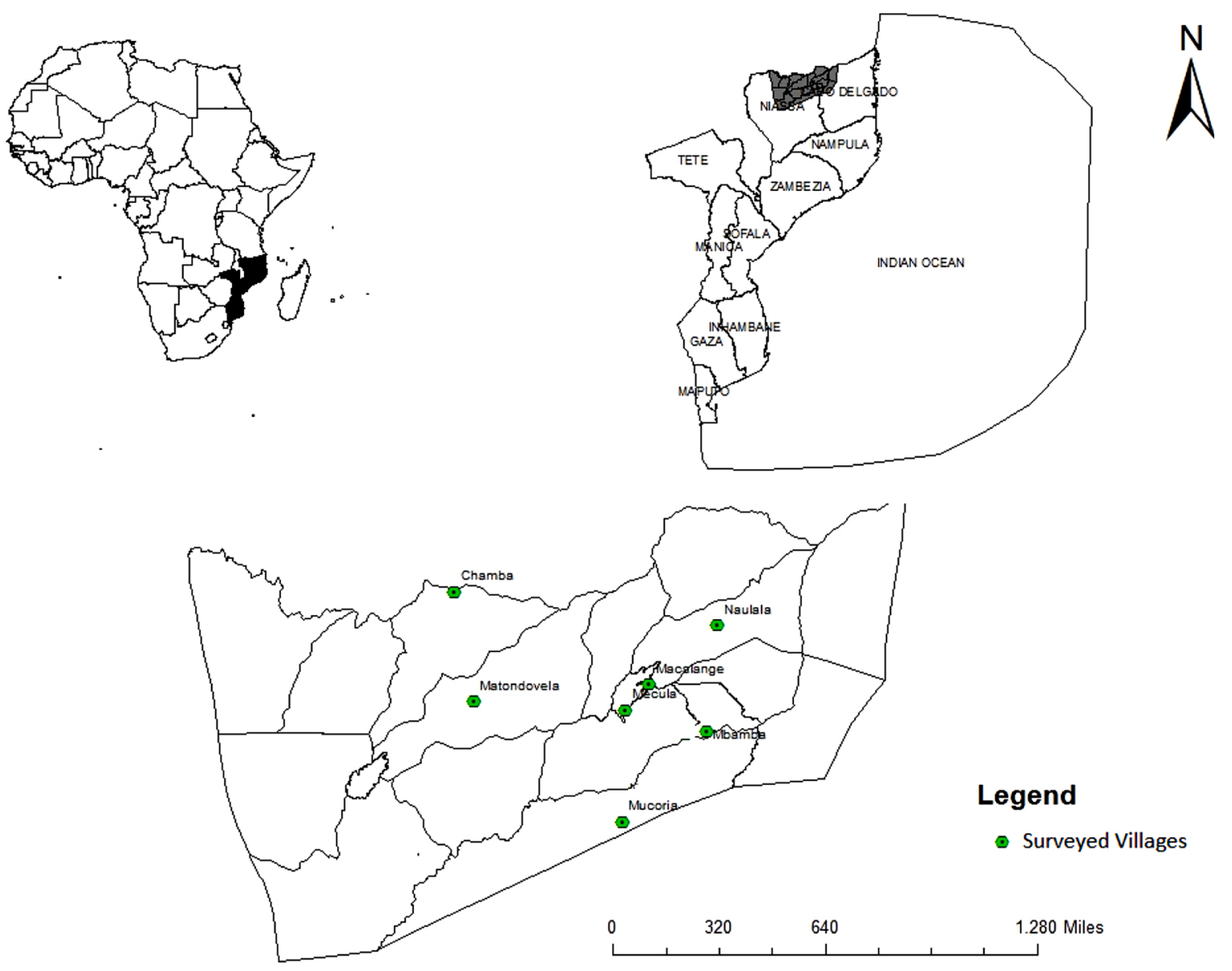

Fig. 1. The location of the Niassa National Reserve and the surveyed villages.

In this research, we used the LFS approach to frame the existing conservation problems in the Niassa National Reserve (NNR), which is a typical example of the above-contextualized problem in PAs of DCs. By identifying (i) the available management options for local economic agents and (ii) the factors that drive these agents' choice of LS and FS, this approach aims to assist policymakers with appropriate measures, which can be used to design and implement more effective conservation policies and strategies in PAs of DCs.

These problems were addressed through the following research questions:

i) Which land management options among the exiting LFS offer the highest potential for diversification and intensification strategies aimed at improving livelihoods and local food security, and which are the factors driving local agents to choose these options?

ii) Which LFS has the potential to mitigate crop raiding and other negative impacts on biodiversity conservation and local resident livelihoods and thereby reduce HWC in the NNR?

iii) Are there any factors that contribute to agricultural intensification or land expansion in the NNR? What are the implications of agricultural intensification and expansion for local agents and biodiversity conservation?

iv) What are the strengths and weaknesses of the LFS approach, and what are its implications for nature conservation policies in the NNR and in other PAs of DCs?
These questions were addressed through a structured survey of households in seven villages located inside the NNR. Householders were asked about several topics related to their LS and FS, losses from crop raiding and their socio-economic and demographic profile.

\section{Methodology}

\subsection{Site location and characterization}

NNR is located in northern Mozambique, between coordinates: $12^{\circ} 38^{\prime} 48.67^{\prime \prime} \mathrm{S} ; 11^{\circ} 27^{\prime} 05.83^{\prime \prime} \mathrm{S}$ and $36^{\circ} 25^{\prime} 21.16^{\prime \prime} \mathrm{E} ; 38^{\circ} 30^{\prime} 23.74^{\prime \prime} \mathrm{E}$ (see Fig. 1). It is the largest PA in Mozambique and the third largest in Africa (Prin et al., 2014; Ribeiro et al., 2008). The reserve covers 42,200 $\mathrm{km}^{2}$ (Mbanze et al., 2019a; Prin et al., 2014), of which over $34,000 \mathrm{~km}^{2}$ are occupied by concession blocks, with additional blocks up for tender in 2019.

The current human population is about 60,000 residents (NCP, 2017), representing more than a two-fold increase in just ten years (NCP, 2015). Most of the population suffers from chronic food insecurity and limited access to basic social services. They rely primarily on subsistence agriculture, bushmeat hunting and harvesting of NTFPs, including fishing, honey-gathering and illegal trade of natural resources, since there are few legal alternatives (NCP, 2017). Agriculture is practised in small plots of 0.4-2 hectares called "machambas" (Landry and Chirwa, 2011). Soils in the reserve are essentially poor and poorly drained (Campbell, 1996; Dewees et al., 2010). Land preparation includes slash-and-burn practices that exacerbate the soil's impoverishment and 
Table 1

Number of households sampled per village.

\begin{tabular}{llll}
\hline Villages & $\begin{array}{l}\text { Number of households } \\
\text { in the village }\end{array}$ & $\begin{array}{l}\text { Number of } \\
\text { households sampled }\end{array}$ & $\begin{array}{l}\text { Sampling } \\
\text { effort (\%) }\end{array}$ \\
\hline Chamba & 50 & 42 & 84.0 \\
Macalange & 132 & 45 & 34.1 \\
Matondovela & 77 & 52 & 67.5 \\
Mbamba & 141 & 62 & 44.0 \\
Mecula & 908 & 56 & 6.2 \\
Mucoria & 131 & 42 & 32.1 \\
Naulala & 170 & 40 & 23.5 \\
TOTAL & 1609 & 339 & 21.1 \\
\hline
\end{tabular}

Source: National census (2015) available at district level.

reduce productivity. These lands are subsequently abandoned after two to four years of cultivation, due to lack of essential nutrients (NCP, 2017). Land preparation starts three months before the rainy season, which extends from November to April. In this hot, dry period, most of the vegetation is dry and prone to wildfires (Mbanze et al., 2015). Rainfall follows a west-east gradient, with about $1200 \mathrm{~mm}$ average annually in the west and $600 \mathrm{~mm}$ in the east. Temperatures are typically high, with monthly averages reaching around $30{ }^{\circ} \mathrm{C}$ in October and November, and dropping to $20-26{ }^{\circ} \mathrm{C}$ in the cold dry season or winter (SRN, 2008). Crop and livestock raiding by wild animals is relatively common (Jorge et al., 2013), and the frequency of raids threatens food security of local residents (NCP, 2018).

The network of PAs has increased substantially in the country in the last 20 years (Ministry for the Coordination of Environmental Affairs (MICOA, 2014)), representing about $26 \%$ of the country's forests surface (Marzoli, 2007). Within the network, the NNR accounts for $5.3 \%$ (ANAC, 2016) of the total area and $44.9 \%$ of conservation areas (Ganzin et al., 2010; Prin et al., 2014). The reserve is one of the few intact miombo savannahs remaining in the world (Ribeiro et al., 2013; WWF, 2012). It is home to 1200 lions, one of only seven remaining PAs that each protect more than 1000 African lions (Panthera leo), and a substantial elephant (Loxodonta Africana) population (Riggio et al., 2013). Unfortunately, poaching and illegal ivory and skin trades represent major threats to conservation, due to (i) increasing demand for ivory in fast-growing Asian economies, particularly China and Thailand (Booth and Dunham, 2014; UNEP et al., 2013); ii) retaliatory killing of raiding animals (Mbanze et al., 2019b; NCP, 2017) and (iii) the increasing of the human population (NCP, 2015). For all these above reasons pointed out, the NNR is an ideal PA in Mozambique, representative of the Miombo savannas, to conduct this research.

\subsection{Data collection}

Data were collected in seven villages within the reserve (Fig. 1 and Table 1). Villages were selected after review the reserve reports, grey literature and meeting with the NNR administration, the Mecula district government, and the Niassa Carnivore Project, to have a more authoritative information and thus select a set of representative villages sample concerning farming and livelihood systems. In this study, a village is defined by the spatial extent of households associated with a village name under the leadership of one village Chairperson (Mackenzie, 2012), which is the lowest administrative unit in Mozambique. The total number of households registered in each village was provided by the NNR administration and Districtal Secretariat of Agriculture and Economic Activities (Secretariado Distrital de Agricultura e Atividades Econômicas - SEDAE), located in the Mecula headquarters. The sample size was uneven among villages because the main objective was to assure sampling representativeness and preserve the theorem, that for a given random and normally distributed population, sample size does not necessarily increase in the same proportion as the population size (Bartlett et al., 2001; Krebs, 2014). Sampling was taken for convenience. A survey was conducted from July to September 2017. During this period, 339 householders (21.07 \%) were surveyed in the seven villages. Most of the surveyed householders $(92.33 \%)$ were men, with age ranging from 18 to 86 years (mean = 43; Std. deviation $=16.52$ ).

\subsubsection{Household survey}

The questionnaire had four sections: 1) general information, which included the location and size of the village; 2) socio-economic background of the household (household size, employment status, income and education); 3) agricultural outputs in the last season (crop harvest and losses for crop raiding), rank of the four top raiding species according to potential loss, the proportion of the harvest of each crop that was sold and market prices, and 4) gathering effort related to NTFPs (frequency of harvesting and its final propose, either for use or sale, quantities and prices if households remembered). We did not measure the size of the farming area to estimate yield per hectare, as most of the agriculture fields were not close to the villages, and households were not able to show their farming borders within time and logistical constraints. The questionnaire was pre-tested with 10 householders in the Mbamba village, and administered to respondents in collaboration with five field assistants and two young locals, who were familiar with the local languages (Cyao, Emakua and Swahili). In order to avoid external bias and/fear of answering some sensitive questions, each household was individually questioned, mostly at home. Before the administration of the questionnaire, oral consent was obtained. Only 5 households were unable to participate in the survey, but they were replaced by others to reach the required sample size. No questionnaire was withdrawn from the analyzes. The full questionnaire instrument appears in Appendix A.

\subsection{Data analysis}

\subsubsection{Agriculture production and prices}

All agricultural outputs and losses were transformed into monetary value and percentage to express the quantities in physical terms and thus allow comparison among farms, LFS and villages (See Appendix B). The average price of each crop (in new metical MZN) ${ }^{2}$ was estimated based on figures provided by the surveyed households (see Section 4 in Appendix A), by dividing the total revenue of crop sold by its respective quantities. This price was subsequently used to derive the Partial Expected Production (PEP) of each crop in monetary values. The PEP was then summed to obtain Total Expected Agriculture Production (TEAP $\left.{ }_{i}\right)$. We also estimated Actual Crop Production $\left(\mathrm{ACP}_{\mathrm{i}}\right)$ (by removing losses from crop raiding from the TEAP), and the Proportion of Crop Sold (PCS), which is the amount of crop sold in MZN, divided by the Actual Crop Production (PCS/ACP ${ }_{i}$ ).

\subsubsection{Typology of Livelihood Systems and Livelihood-System patterns of different villages}

2.3.2.1. Gathering effort and effort by gathering activity. The frequency of participation of the respondent's household in each gathering activity was estimated based on the selection of a specified frequency class option in Section 4 of the questionnaire: 365 days/year were allocated for those that selected the daily option; 52 days/year for the weekly option; 12 days/year for the monthly option; 2 days/year for the semester option; and 1 day/year for the yearly option. This allocation of days/year was done for all 10 gathering activities included in the questionnaire, yielding 10 indicators of yearly gathering effort per activity. By

\footnotetext{
${ }^{2}$ New Metical (MZN) is the Mozambican currency. As of $25^{\text {th }}$ November 2019 the exchange rate was: One US dollar (\$1) was equivalent to $63.25 \mathrm{MZN}$. One British Pound ( $1 £$ ) was equal to $81.43 \mathrm{MZN}$, while one Euro $(1 €)$ was equivalent to 69.67 MZN. Source: https://www1.oanda.com/lang/pt/fx-for-business/histo rical-rates (OANDA - solutions for business)
} 
summing frequencies across all activities, we computed the total number of days per year in all gathering activities, which can be interpreted as a rough estimate of total yearly gathering effort. These indicators of gathering effort per activity $\left(\mathrm{GEA}_{\mathrm{i}}\right.$, where ${ }_{\mathrm{i}}$ is the activity index) and total gathering effort (TGE) were then divided by the total expected agricultural production of the household (TEAP, in metical/year) to express gathering effort in proportion to agricultural output (days/metical); that is GEA $_{\mathrm{i}} /$ TEAP for each gathering activity and TGE/TEAP for all gathering activities. These ratios can be interpreted as the relative importance of gathering as compared to agriculture.

The Crop Raiding Index 1 , which predicts the potential damage that is likely to occur at farm level, was based on the top four crop raiding species (elephants, buffalo, baboons and bushpigs), ranked by the surveyed households (Rank $k_{i}$, where $i$ vary from 1 to 4 ). The class of potential damage to each crop raiding (C), was taken from the literature (Mackenzie, 2012; Tufa et al., 2018) and the authors' personal experience. Elephants and buffalos were considered the most damaging animals $(C=2)$, followed by baboons and bushpigs $(C=1)$.

Crop raiding $1=\sum_{i=1}^{4} \operatorname{Rank}_{i}^{*} C_{i}$

Crop Raiding Index 1 was then compared to Crop Raiding Index 2, which is the faunal density reported in the NNR management plan at the block level (SRN, 2008). We used both indexes, because (i) Crop raiding index 2 is likely out of date, as the last faunal inventory in our possession was conducted in 2005; (ii) the inventory was not conducted at the village level to cover damages reported by households; and (iii) there are numerous reports highlighting decreases of wild animals in the reserve in the lasts 10 years, especially for elephants (Booth and Dunham, 2014; Brennan and Kalsi, 2015; Jorge et al., 2013).

2.3.2.2. Developing a livelihood system typology. To identify different livelihood systems, we classified all surveyed households according to their main sources of income and their relative weights in the total (monetary and in-kind) income of the household. The relative weight of these sources of income was measured in different ways for the different major income-generating activities, depending on data we had access to. First, all households that (1) employed and depended only on wages earned, (2) have not been involved in gathering activities, and (3) had not been running a farm were included in the "Employees" category. All other households were included in a cluster analysis based on ratios of gathering effort per activity (and total gathering effort) to total expected agricultural production, that is $\mathrm{GEA}_{\mathrm{i}} / \mathrm{TEAP}$, for each gathering activity and TGE/TEAP for all gathering activities. Only four $\mathrm{GEA}_{\mathrm{i}} / \mathrm{TEAP}$ variables were used $(\mathrm{i}=$ traditional medicines, firewood, edible insects and bushmeat) because many other gathering activities, such as gathering poles, stakes, bamboos or grass for roofing are very much linked to building or repairing activities, which for the same household, can vary very greatly across years and thus, are not good structural indicators of the household economy. A hierarchical cluster analysis was performed using Ward's method and the Minkowski measure of dissimilarity (Legendre and Legendre, 2003).

2.3.2.3. Livelihood-system patterns across villages. To describe the LS pattern of each village, a cross-tabulation of LS and villages was performed to verify whether the null hypothesis of similar patterns of LS across villages can be rejected. After detecting any significant relationship, a post hoc cellwise test was performed to find out which livelihood systems were above/below what would be expected by chance in each village (García-Pérez and Núñez-Antón, 2003; Sharpe, 2015).

\subsubsection{Developing Farming System typology and patterns across villages}

The ratio between Partial Expected Production and Total Expected Agriculture Production $\left(\mathrm{PEP}_{\mathrm{i}} / \mathrm{TEAP}_{\mathrm{i}}\right) * 100$, was used to develop the typology of FS, based on agricultural crops (see Appendix 1, Section 3). Fish and honey were assigned in the farming system category, despite being NTFPs (see Section 4 in the Appendix 1), because: (i) we have
Table 2

Predictors and drivers of Livelihood and Farming System in the NNR.

\begin{tabular}{|c|c|c|c|c|}
\hline $\begin{array}{l}\text { Variable name/ } \\
\text { code }\end{array}$ & Type & $\begin{array}{l}\text { Unity of } \\
\text { measuring/ } \\
\text { Class }\end{array}$ & Min-Max & Mean (SD) \\
\hline \multicolumn{5}{|c|}{ Livelihood system } \\
\hline $\begin{array}{l}\text { Household } \\
\text { size }^{*,+}\end{array}$ & Numerical & NA & $1-15$ & $4.93(2.05)$ \\
\hline Education $^{\dagger}$ & Ordinal & 7 classes & $\begin{array}{l}\text { Illiterate }(0)- \\
\text { BSc }(6)\end{array}$ & $1(1.11)$ \\
\hline Age $^{*}$ & Numerical & NA & $18-86$ & $43(16.52)$ \\
\hline $\begin{array}{l}\text { Economic size } \\
\text { of the farm* }\end{array}$ & Numerical & MZN & $\begin{array}{l}0- \\
246092.46\end{array}$ & $\begin{array}{l}29558.97 \\
(32350.8)\end{array}$ \\
\hline $\begin{array}{l}\text { Crop riding } \\
\text { (1)* }\end{array}$ & Ordinal & NA & $13-17$ & $15.24(1.89)$ \\
\hline $\begin{array}{l}\text { Crop riding } \\
(2)^{*}\end{array}$ & Ordinal & NA & $3-5$ & $4.17(0.98)$ \\
\hline Crop lost ${ }^{\dagger}$ & Numerical & $\%$ & $35-66.0$ & $45.32(9.79)$ \\
\hline Crop sold $^{\dagger}$ & Categorical & dummy & $0-1$ & NA \\
\hline \multicolumn{5}{|c|}{ Farming system } \\
\hline Flatland $^{\dagger}$ & Numerical & $\%$ & $5.8-33.40$ & $18.87(0.45)$ \\
\hline $\begin{array}{l}\text { Distance to the } \\
\text { market }^{\dagger}\end{array}$ & Numerical & Hours (h) & $0.00-7.00$ & $4.52(3.04)$ \\
\hline $\begin{array}{l}\text { Total } \\
\text { population }\end{array}$ & Numerical & NA & $234-13173$ & $\begin{array}{l}3064.86 \\
(4804.35)\end{array}$ \\
\hline Rainfall ${ }^{\dagger}$ & Numerical & $\mathrm{mm}$ & $\begin{array}{l}1040.05- \\
1867.0\end{array}$ & $\begin{array}{l}1241.35 \\
(259.81)\end{array}$ \\
\hline
\end{tabular}

\footnotetext{
Predictors used to describe LS through Analysis of Variance.

† Predictors/drivers used to describe LFS through the Multinomial Logistic
} Model.

captured quantities and price at the household level since a considerable number of households reported selling a part of their production; and (ii) they are very profitable activities, with some households devoting a large portion of their time doing those activities, as there is a local market available. For instance, a litter of honey can bring up to \$2 USD dollars in the local market (NCP, 2017).

2.3.3.1. Development of farming system typology. The proportion of the dominant crop in the FS was used to assign FS. By convention, we designated specialized FS when the proportion of the dominant crop was approximately equal or greater than to $50 \%$ of the TEAP ${ }_{i}$ while mixed FS were those with no clear dominant crop in the system. FS were assessed through Cluster Analysis on the household data of $\mathrm{PEP}_{\mathrm{i}} / \mathrm{TEAP}_{\mathrm{i}}$, performed using Ward's method and the Minkowski index of dissimilarities (Legendre and Legendre, 2003).

2.3.3.2. Farming system patterns across villages. To describe FS pattern at village level, a cross-tabulation between FS and villages was assembled and tested to verify whether the null hypothesis of similar patterns of FS across villages can be rejected. Post hoc cellwise tests were performed to find out which FS were above/below what would be expected by chance in each village (García-Pérez and Núñez-Antón, 2003; Sharpe, 2015).

\subsubsection{Predictors and drivers of livelihood and farming systems}

Predictors and drivers of LFS were grouped as: (i) socio-economic (size of the family, level of education of the household head, total population per village, distance to the nearest market and crop sold by the household). The Mecula Headquarters was used as the reference for the nearest developed market. Thus household heads living in Mecula are on average $0 \mathrm{~h}$ to the nearest market. Crop sold was coded as a dummy variable $(1=$ if household sold the crop and $0=$ otherwise). The Proportion of Crop Lost per Farm (PCLF) was the ratio between total monetary losses and Total Expected Agriculture Production (TEAPi); and (ii) biophysical drivers (availability of flatland for agriculture, average annual rainfall and crop raiding index 1 and 2). The percentage 
Table 3

Livelihood systems, their characteristics, and village-level patterns.

\begin{tabular}{|c|c|c|c|c|c|c|c|}
\hline & $\begin{array}{l}\text { Gatherers } \\
8,0 \%\end{array}$ & $\begin{array}{l}\text { Hunters } \\
35.1 \% \\
\end{array}$ & $\begin{array}{l}\text { Farmers } \\
52.2 \% \\
\end{array}$ & $\begin{array}{l}\text { Employees } \\
4.7 \% \\
\end{array}$ & $\begin{array}{l}\text { Total } \\
\mathrm{N}=339\end{array}$ & Alf $(\alpha)$ & $\mathrm{Eta}^{2}$ \\
\hline \multicolumn{8}{|c|}{ Gathering effort per activity and total gathering effort in proportion of total expected agricultural production $\left(\mathrm{GEA}_{\mathrm{i}} / \mathrm{TEAP}\right)$} \\
\hline Traditional Medicines & 0.17 & 0.04 & 0.01 & - & 0.036 & $0.000 * * *$ & 0.075 \\
\hline Firewood & 2.83 & 0.54 & 0.16 & - & 0.524 & $0.000 * * *$ & 0.719 \\
\hline Edible Insects & 0.04 & 0.01 & 0.00 & - & 0.006 & $0.000^{* * *}$ & 0.072 \\
\hline Bush meat & 0.01 & 0.04 & 0.01 & - & 0.018 & $0.000^{* * *}$ & 0.051 \\
\hline Total gathering effort (all activities) & 3.81 & 1.06 & 0.27 & - & 0.859 & $0.000 * * *$ & 0.746 \\
\hline \multicolumn{8}{|c|}{ Description of average household per livelihood system } \\
\hline Farm economic size (TEAP in metical/year) & 7461 & 13,462 & 46,424 & - & 29,559 & $0.000 * * *$ & 0.305 \\
\hline Household size & 4.9 & 4.4 & 5.3 & 4.6 & 4.9 & $0.001^{* * *}$ & 0.047 \\
\hline Age & 43 & 42 & 44 & 34 & 43 & 0.057 & 0.022 \\
\hline Education level & low & low & low & high & low & $0.000^{* * *}$ & 0.195 \\
\hline Distance to the Market & 4.6 & 4.4 & 4.6 & 2.1 & 4.4 & $0.023^{*}$ & 0.028 \\
\hline Crop riding (1) & 15.6 & 15.2 & 15.3 & 13.9 & 15.2 & $0.000 * * *$ & 0.066 \\
\hline Crop riding (2) & 4.4 & 4.0 & 4.3 & 3.5 & 4.17 & $0.001^{* *}$ & 0.047 \\
\hline \multicolumn{3}{|c|}{ Proportions of different livelihood systems in each village (\%) } & & & \multicolumn{3}{|l|}{$\mathrm{N}$} \\
\hline Chamba & 4.8 & 31.0 & 59.5 & 4.8 & 42 & & \\
\hline Macalange & 4.4 & 24.4 & 68.9 & 2.2 & 45 & & \\
\hline \multirow[t]{2}{*}{ Matondovela } & 0.0 & 30.8 & 65.4 & 3.8 & 52 & & \\
\hline & - & & & & & & \\
\hline \multirow[t]{2}{*}{ Mbamba } & 14.5 & 38.7 & 45.2 & 1.6 & 62 & & \\
\hline & + & & & & & & \\
\hline \multirow[t]{2}{*}{ Mecula } & 8.9 & 30.4 & 42.9 & 17.9 & 56 & & \\
\hline & & & & +++ & & & \\
\hline \multirow[t]{2}{*}{ Mucoria } & 2.4 & 69.0 & 28.6 & 0.0 & 42 & & \\
\hline & & +++ & - & & & & \\
\hline \multirow[t]{2}{*}{ Naulala } & 20.0 & 22.5 & 57.5 & 0.0 & 40 & & \\
\hline & ++ & & & & & & \\
\hline Total Villages & $8.0 \%$ & $35.1 \%$ & $52.2 \%$ & $4.7 \%$ & 339 & & \\
\hline
\end{tabular}

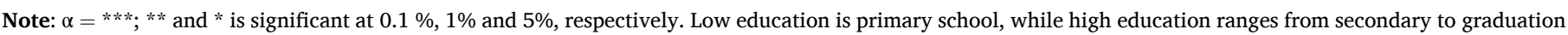

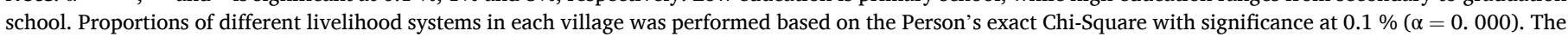

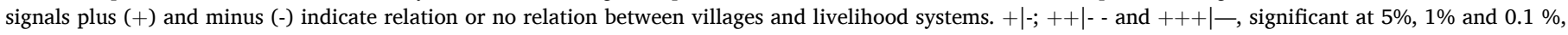
respectively.

of flatland suitable for rice cultivation (with slope between 0-2\%) was derived from NNR Digital Terrain Model, ${ }^{3}$ using a $4 \mathrm{Km}$ buffer from the centre of each village (excludes mountains and rivers). This $4 \mathrm{Km}$ distance range, was selected through satellite images of farming clusters (land use pattern) closer to the village. Some predictors/drivers (age, farm economic size, Crop Raiding Index 1 and 2), with meaningful explanations, but which did not fit in the LS model were used to describe the average size of the LS. Table 2 provides detailed information on all predictors and drivers of LFS. Some predictors and drivers were analysed at the village level, while others were analysed at the household level.

\subsubsection{Livelihood and farming systems models}

A Multinomial Logistic Model was applied to investigate the importance of each predictor and driver of LS and FS. The importance of each of the variables in the fitted model was detected based on the loglikelihood, likelihood ratio, Nagelkerke and Cox\&Snell Pseudo R-square. Predictors were selected based on their significance in the model and possible meaningful interpretation. The importance of each predictor included in the model was assessed at $\mathrm{p} \leq 0.05$ level of significance.

\subsubsection{Effect of rainfall and population in agricultural intensification}

Measuring land-use intensity is a multifaceted and multidimensional topic, that gained more attention in the last years due to the growing demand for food. This food growth demand in addition to the environmental concerns, led to a search for sustainable solutions to intensify food production, that respect land restrictions, and minimize adverse effects on biodiversity, water and environment (Erb et al., 2013; Kuemmerle et al., 2013). There are different methods to measure

\footnotetext{
${ }^{3}$ https://www.eorc.jaxa.jp/ALOS/en/aw3d30/.
}

land-use intensity, mostly measuring input and/or output intensity throughout different surrogates variables, depending on the final purpose and availability of data (Erb et al., 2013; Levers et al., 2016). In this study, we want to measure agricultural intensity per hectare, to understand whether the growth of human population in the reserve is pressing for intensification, given the existing land restrictions.

Since it was not possible to capture the yield of each crop per unit area (hectare), an artefact was applied to have a broad idea regarding the effect of population growth and rainfall in agricultural intensification. The artefact consisted of depicting a diagram of the total population at the village level and rainfall $v s$ the average number of households fed per hectare of cropland. Agricultural intensity was measured in people/hectare, as the ratio between the average household size with a farm and the total cropland area. The resort of secondary data from the National Agricultural Census (Instituto Nacional de Estatística (INE, 2011)), provided information about the average cropland area per household head at the village level.

\subsubsection{Losses from crop raiding and their patterns across villages and LFS}

The percentage of perceived crop lost was a ratio between crop loss from crop raiding and Partial Expected Production $\left(\mathrm{PEP}_{\mathrm{i}}\right)$. Those individual ratios were then expanded to FS and village levels to understand whether crop-raiding influences LFS strategies (e.g. what crop to plant or shift to off-farm activities). To depict the interrelation among LFS, the potential damage from crop raiding (Crop Raiding Indexes), losses from crop raiding (actual damage), and the effect of different protective strategies (e.g. electro-fence), at the village level. A comparable measure was created by transforming potential and actual damage into ordinal indexes (low, medium and high). These ordinal indexes were built based solely on the information in the present study. Thus, these indexes are strictly relative and do not allow comparison with other works. This procedure was 
Table 4

Multinomial logistic regression model of livelihood system choice.

\begin{tabular}{|c|c|c|c|c|c|c|}
\hline Livelihood system & Drivers & Coefficient B & Std. Error & Z-values & Alf $(\alpha)$ & $\operatorname{Exp}(B)$ \\
\hline \multirow{5}{*}{ Hunters } & Intercept & 3.195 & 0.806 & 15.735 & $0.000 * * *$ & \\
\hline & Household size & -0.236 & 0.069 & 11.775 & $0.001^{* *}$ & 0.790 \\
\hline & Education & -0.096 & 0.120 & 0.639 & $0.424^{\mathrm{NS}}$ & 0.909 \\
\hline & Crop lost & -0.027 & 0.014 & 3.618 & $0.057^{\mathrm{NS}}$ & 0.973 \\
\hline & Crop sold $=$ Yes & -1.995 & 0.282 & 50.146 & $0.000^{* * *}$ & 0.136 \\
\hline \multirow{5}{*}{ Gatherers } & Intercept & 3.606 & 1.359 & 7.040 & $0.008^{* *}$ & \\
\hline & Household size & -0.100 & 0.102 & 0.951 & $0.330^{\mathrm{NS}}$ & 0.905 \\
\hline & Education & -0.293 & 0.216 & 1.835 & $0.176^{\mathrm{NS}}$ & 0.746 \\
\hline & Crop lost & -0.079 & 0.028 & 7.944 & $0.005^{* *}$ & 0.924 \\
\hline & Crop sold $=$ Yes & -2.242 & 0.479 & 21.955 & $0.000 * *$ & 0.106 \\
\hline \multirow{5}{*}{ Employees } & Intercept & -1.870 & 2.225 & 0.706 & $0.401^{\mathrm{NS}}$ & \\
\hline & Household size & -0.187 & 0.153 & 1.507 & $0.220^{\mathrm{NS}}$ & 0.829 \\
\hline & Education & 1.106 & 0.250 & 19.601 & $0.000^{* * *}$ & 3.022 \\
\hline & Crop lost & -0.021 & 0.043 & 0.232 & $0.630^{\mathrm{NS}}$ & 0.979 \\
\hline & Crop sold $=$ Yes & -22.149 & 0.000 & & & $2.403 * 10^{9}$ \\
\hline
\end{tabular}

Note: Farmers is the reference category; $\alpha=* * *$ is significant at $0.1 \%$, $* *=1 \%, *=5 \%$, NS $=$ not significant.

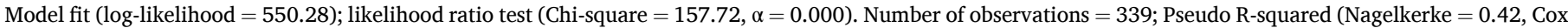
and Snell $=0.37$ ).

done to allowed us to compare the level of potential and actual damages among villages, as well as have a broader picture of how a set of farms within a village perceive the available options to overcome crop raiding.

\section{Results}

\subsection{Livelihood Systems and their village-level patterns}

Four LS have been identified in the NNR: gatherers, hunters, farmers, and employees (Table 3). Gatherers exhibit the highest level of gathering effort in proportion to agricultural output, except for bushmeat, and present a relatively low average expected agricultural production per household. They represent a small fraction of households in the sample (8\%) but reach a higher proportion (up to $20 \%$ ) in Mbamba and Naulala villages. Hunters have the highest level of hunting effort in proportion to agriculture, and they have levels of gathering effort higher than farmers for all other gathering activities. Hunters have the smallest expected agricultural output and household size; they represent, overall, slightly more than $1 / 3$ of all households, but they reach $70 \%$ in Mucoria. Farmers have the lowest levels of effort in each and all gathering activities in proportion to agricultural output. They have the largest average agricultural output and household size. Employees who depend

Table 5

Farming systems (FS), their characteristics and village-level patterns.

\begin{tabular}{|c|c|c|c|c|c|c|c|}
\hline Crop & $\begin{array}{l}\text { Specialized Maize } \\
93(28.8)\end{array}$ & $\begin{array}{l}\text { Specialized Rice } \\
80(24.8)\end{array}$ & $\begin{array}{l}\text { Mixed Crops } \\
128(39.6)\end{array}$ & $\begin{array}{l}\text { Specialized Sorghum } \\
22(6.8)\end{array}$ & $\begin{array}{l}\text { Total } \\
323(100.0)\end{array}$ & Alf $(\alpha)$ & $\mathrm{Eta}^{2}$ \\
\hline \multicolumn{8}{|c|}{ Partial Expected Production of each crop in proportion to the Total Expected Production (PEP/TEAP in \%) } \\
\hline Maize & 71.2 & 31.6 & 32.0 & 19.9 & 42.4 & $0.000 * * *$ & 0.598 \\
\hline Peanut & 1.2 & 2.0 & 11.7 & 8.0 & 6.0 & $0.000^{* * *}$ & 0.212 \\
\hline Cassava & 4.0 & 5.7 & 4.6 & 4.6 & 4.7 & $0.702^{\mathrm{NS}}$ & 0.004 \\
\hline Rice & 13.5 & 48.8 & 7.5 & 7.5 & 19.5 & $0.000^{* * *}$ & 0.644 \\
\hline Cowpea & 1.9 & 1.4 & 10.5 & 0.7 & 5.1 & $0.000^{* * *}$ & 0.166 \\
\hline Pea & 1.4 & 1.5 & 5.6 & 3.6 & 3.2 & $0.001 * *$ & 0.047 \\
\hline Sorghum & 1.9 & 2.6 & 8.9 & 53.2 & 8.3 & $0.000^{* * *}$ & 0.670 \\
\hline Millet & 0.1 & 0.1 & 3.1 & 0.3 & 1.3 & $0.001 * *$ & 0.050 \\
\hline Sesame & 1.3 & 2.3 & 5.3 & 0.9 & 3.1 & $0.003^{* *}$ & 0.043 \\
\hline Sweet potato & 1.2 & 1.3 & 2.3 & 0.1 & 1.6 & $0.253^{\mathrm{NS}}$ & 0.013 \\
\hline Vegetables & 1.9 & 0.6 & 3.1 & 0.0 & 1.9 & $0.033^{*}$ & 0.027 \\
\hline Tobacco & 0.0 & 1.2 & 2.5 & 0.0 & 1.3 & $0.106^{\mathrm{NS}}$ & 0.019 \\
\hline Honey & 0.4 & 0.2 & 2.5 & 1.0 & 1.2 & $0.019 *$ & 0.031 \\
\hline Fish & 0.2 & 0.7 & 0.4 & 0.0 & 0.4 & $0.558^{\mathrm{NS}}$ & 0.006 \\
\hline \multicolumn{5}{|c|}{ Proportions of different farming systems in each village (\%) } & $\mathrm{N}$ & & \\
\hline \multirow[t]{2}{*}{ Chamba } & 40.0 & 42.5 & 17.5 & 0.0 & 40 & & \\
\hline & + & ++ & - & - & & & \\
\hline \multirow[t]{2}{*}{ Macalange } & 31.8 & 47.7 & 20.5 & 0.0 & 44 & & \\
\hline & & ++ & - & - & & & \\
\hline \multirow[t]{2}{*}{ Matondovela } & 68.0 & 22.0 & 8.0 & 2.0 & 50 & & \\
\hline & +++ & & - & & & & \\
\hline \multirow[t]{2}{*}{ Mbamba } & 13.1 & 11.5 & 59 & 16.4 & 61 & & \\
\hline & - & - & ++ & ++ & & & \\
\hline Mecula & 30.4 & 30.4 & 39.1 & 0.0 & 46 & & \\
\hline \multirow[t]{2}{*}{ Mucoria } & 2.4 & 2.4 & 90.5 & 4.8 & 42 & & \\
\hline & - & - & +++ & & & & \\
\hline \multirow[t]{2}{*}{ Naulala } & 15.0 & 22.5 & 40.0 & 22.5 & 40 & & \\
\hline & - & & & ++ & & & \\
\hline Total & 28.8 & 24.8 & 39.6 & 6.8 & 323 & & \\
\hline
\end{tabular}

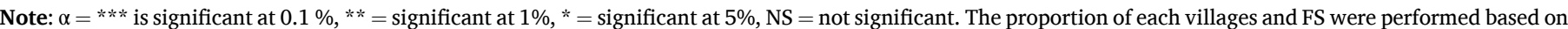

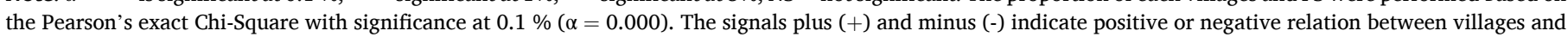
livelihood systems.

$+|-;++|--$ and $+++\mid-$, significant at $5 \%, 1 \%$ and $0.1 \%$, respectively. 
Table 6

Multinomial logistic regression model of farming system choice.

\begin{tabular}{|c|c|c|c|c|c|c|}
\hline FS & Drivers & Coefficients (B) & Std. Error & Z-Value & $\operatorname{Sig}(\alpha)$ & $\operatorname{Exp}(B)$ \\
\hline \multirow{5}{*}{ Specialized rice } & Intercept & -32.463 & 5.031 & 41.644 & $0.000^{* * *}$ & \\
\hline & Proportion of flatland & 0.270 & 0.044 & 38.426 & $0.000^{* * *}$ & 1.310 \\
\hline & Distance to the market & -0.091 & 0.071 & 1.643 & $0.200^{\mathrm{NS}}$ & 0.913 \\
\hline & Total population & -0.004 & 0.001 & 41.932 & $0.000^{* * *}$ & 0.996 \\
\hline & Rainfall & 0.025 & 0.004 & 41.710 & $0.000^{* * *}$ & 1.026 \\
\hline \multirow{5}{*}{ Specialized maize } & Intercept & -38.552 & 4.891 & 62.131 & $0.000 * * *$ & \\
\hline & Proportion of flatland & 0.270 & 0.044 & 37.383 & $0.000^{* * *}$ & 1.310 \\
\hline & Distance to the market & 0.084 & 0.069 & 1.480 & $0.224^{\mathrm{NS}}$ & 1.088 \\
\hline & Total population & -0.004 & 0.001 & 59.786 & $0.000^{* * *}$ & 0.996 \\
\hline & Rainfall & 0.030 & 0.004 & 62.814 & $0.000 * * *$ & 1.031 \\
\hline \multirow{5}{*}{ Specialized sorghum } & Intercept & 12.775 & 13.455 & 0.902 & 0.342 & \\
\hline & Proportion of Flatland & -0.039 & 0.079 & 0.249 & $0.618^{\mathrm{NS}}$ & 0.961 \\
\hline & Distance to the market & 0.358 & 0.195 & 3.369 & $0.066^{\mathrm{NS}}$ & 1.430 \\
\hline & Total population & 0.002 & 0.002 & 0.780 & $0.377^{\mathrm{NS}}$ & 1.002 \\
\hline & Rainfall & -0.015 & 0.011 & 1.784 & $0.182^{\mathrm{NS}}$ & 0.985 \\
\hline
\end{tabular}

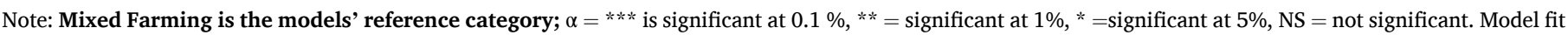

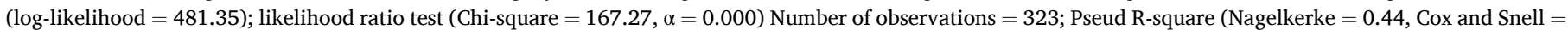
0.40).

mostly on wages, are 10 years younger than all other LS types, and they held the highest educational level. These employees predominantly live in the Mecula village and have the lowest level of both crop-raiding indexes. They represent less than $5 \%$ of the households, except in Mecula where they reach $18 \%$.

All variables used to describe livelihood systems (except age) are significantly different across livelihood types $(\alpha<0.05)$. However, the variance across types is higher than the variance within types $\left(\mathrm{Eta}^{2}>\right.$ 0.50) only for the proportion of total gathering effort and firewood gathering effort.

\subsubsection{Predictors of livelihood system choice}

The fact that (1) there are significant differences across LS at household and village-level, attributes that have not been used in the cluster analysis, and (2) there is a clear geographic pattern of LS at the village level suggests that household choice of LS can be associated to household and village-related variables that can be interpreted as either drivers (opportunities and constraints) or consequences of LS choice. Thus, we use here the terms predictor or co-variate for these variables and postpone this interpretation for the discussion.

The estimated multinomial logit model of LS choice is presented in Table 4. The size of the household and the fact that the head of household sold agricultural output are negatively and significantly $(\mathrm{P}<0.01)$ related to Hunters as compared to Farmers. The village-level proportion of crops lost to wild fauna and selling agricultural output are also negative and significant $(\mathrm{P}<0.01)$ predictors of Gatherers in comparison to the Farmers. Finally, education is a positive and significant $(\mathrm{P}<$ 0.001) predictor of the Employees LS.

Reading these results for the reference category in the model (farmers), we verify that the size of the household is positively associated with choosing the Farmers LS as opposed to the Hunters LS. Likewise, being a Farmer as opposed to Hunter or Gatherer LS increases the likelihood of selling agricultural output. Finally, the proportion of crop lost to crop-raiding is positively associated with the Farmers LS.

\subsection{Farming systems and their village-level patterns}

Four farming systems (FS) have been identified in the NNR (Table 5): (i) Specialized Maize FS, where maize represents nearly $3 / 4$ of the total expected production; (ii) Specialized Rice FS, with rice representing approximately $50 \%$ of the total expected output; (iii) Mixed Crops FS, where there is no clear dominant crop, but maize represents almost $1 / 3$ of the total expected production, followed by peanuts (12\%) and cowpeas (11\%); and (iv) Specialized Sorghum FS, where sorghum represents more than half of the total expected production. Approximately 29
$\%$ of all farms in our sample practice the Specialized Maize FS, a figure that rises to $40 \%$ in Chamba and $68 \%$ in Matondovela. About $25 \%$ of the households are specialized in Rice, which rises to $43 \%$ in Chamba and $48 \%$ in Macalange. The Mixed Crops FS is the most frequent in the Reserve, $40 \%$, a percentage that rises to $59 \%$ in Mbamba and $90 \%$ in Mucoria. Only $7 \%$ of the farms are Specialized in Sorghum, a figure that rises to $16 \%$ in Mbamba and $23 \%$ in Naulala.

All main variables that characterize FS (proportions of maize, rice, and sorghum in the total expected production) are significantly ( $\mathrm{p}<$ 0.001) different across FS. The proportion of variance across FS for all these three variables is high, representing more than half of total variance (squared ETA $\geq 0.60$ ). Maize and rice are relevant crops in other FS in addition to the ones specialized in these crops.

\subsubsection{Predictors of farming system choice}

The estimated multinomial logistic model of FS choice is represented in Table 6. The availability of flatland and rainfall were the main drivers for choosing either the Specialized Maize or Rice FS as opposed to the Mixed Crops FS $(\alpha=0.000)$. The increase of population in the village significantly ( $\alpha=0.000$ ) reduces the likelihood of choosing the Specialized Maize or Rice FS in relation to the Mixed Crops FS, suggesting that population growth stimulates diversification of activities rather than specialization.

Distance to the market has seemingly no significant effect on FS choice, although there is an almost significant positive effect on choosing the Specialized Sorghum FS. Increasing rainfall reduces the likelihood of choosing the Specialized Sorghum FS as opposed to the Mixed Crops FS, an effect that is not statistically significant. There is a significant $(\alpha=0.000)$ negative effect of rainfall on the likelihood of choosing the Specialized Sorghum FS as opposed to the Specialized Maize or Rice FS. Likewise, population size increases the likelihood of choosing the Specialized Sorghum FS as opposed to the Mixed crops, an effect that is not statistically significant. However, there is a significant ( $\alpha=0.000$ ) positive effect of population on the likelihood of choosing the Specialized Sorghum FS as opposed to the Specialized maize or rice FS.

\subsection{Population size, rainfall levels and agricultural intensity}

Fig. 2 depicts the effects of population size and rainfall on agricultural intensity. It can be observed that in the four villages with higher rainfall (rainfall $\geq 1185 \mathrm{~mm}$ ), there is a trend suggesting that increased population is pressing for agricultural intensification, that is: raising the number of people fed per hectare of cropland. Mecula, which has by far the largest population size, has also the highest agricultural intensity 


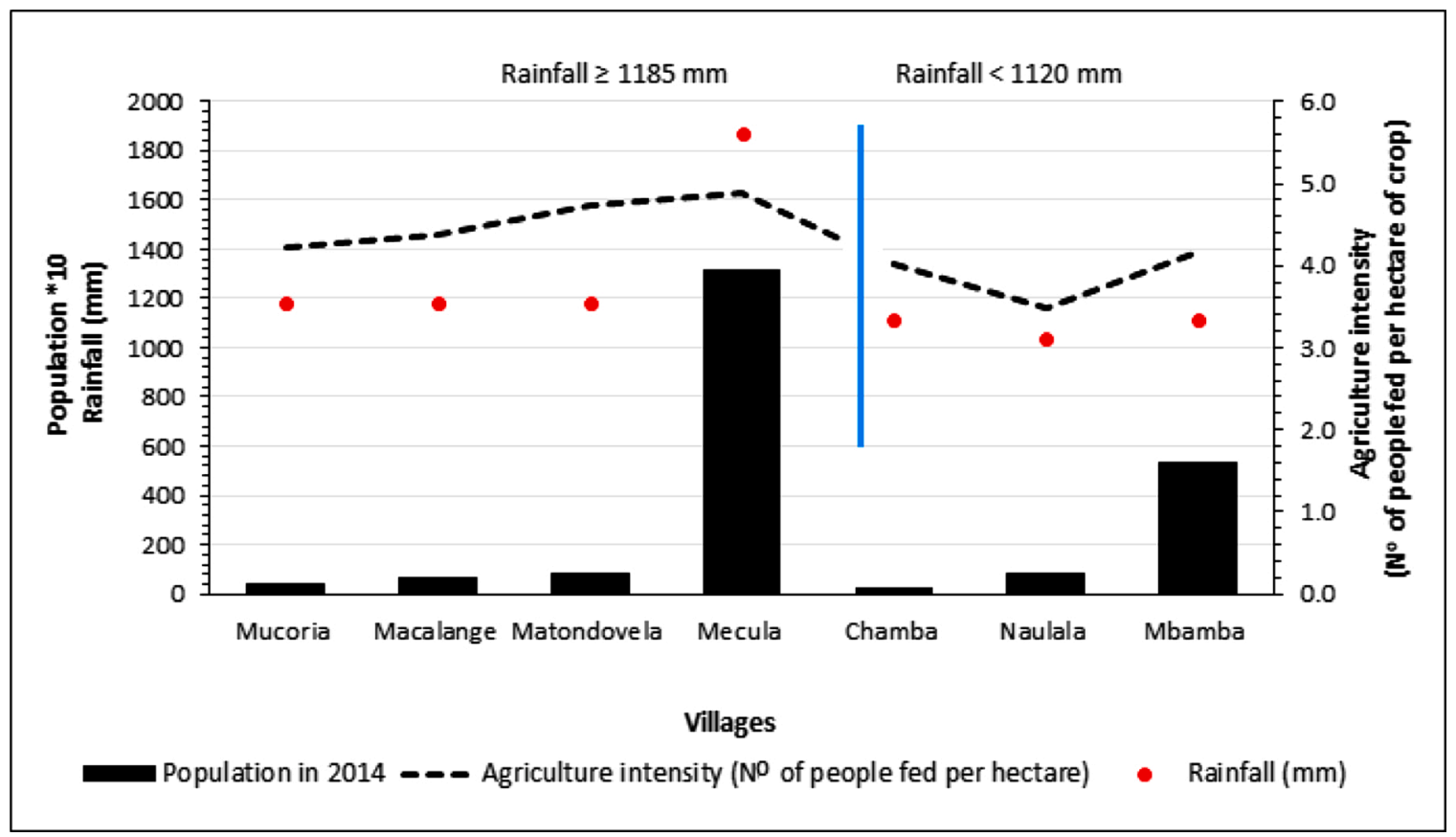

Fig. 2. Effects of population size and rainfall on agriculture intensity across the seven surveyed villages in Niassa National Reserve. Rainfall is the major limiting factor for intensification, especially for those villages where the predominant FS is Specialized Sorghum.

Table 7

Proportion of perceived crop lost to crop raiding per crop and FS (in percentage of total expected production).

\begin{tabular}{|c|c|c|c|c|c|c|c|}
\hline \multirow[b]{2}{*}{ Crops } & \multicolumn{4}{|l|}{ Farming system } & \multirow[b]{2}{*}{ Total } & \multirow[b]{2}{*}{ Alf $(\alpha)$} & \multirow[b]{2}{*}{$\mathrm{Eta}^{2}$} \\
\hline & Specialized Maize & Specialized Rice & Mixed Crops & Specialized Sorghum & & & \\
\hline Maize & 45.7 & 50.7 & 47.5 & 37.9 & 46.8 & $0.016^{* *}$ & 0.033 \\
\hline Peanut & 51.3 & 38.3 & 42.5 & 24.0 & 41.1 & 0.352 & 0.026 \\
\hline Cassava & 49.1 & 36.9 & 40.7 & 41.2 & 42.2 & 0.262 & 0.032 \\
\hline Rice & 45.2 & 52.7 & 52.3 & 48.5 & 50.9 & 0.173 & 0.024 \\
\hline Cowpea & 59.8 & 46.5 & 64.6 & 57.1 & 62.4 & 0.869 & 0.007 \\
\hline Pea & 34.0 & 72.1 & 63.2 & 45.3 & 58.2 & 0.101 & 0.091 \\
\hline Sorghum & 45.0 & 31.5 & 45.5 & 37.5 & 40.3 & 0.492 & 0.018 \\
\hline Millet & 0.0 & 19.0 & 56.2 & 0.0 & 50.9 & 0.281 & 0.122 \\
\hline Sesame & 28.8 & 30.4 & 41.5 & 14.7 & 36.2 & 0.517 & 0.042 \\
\hline Sweet potato & 53.3 & 38.9 & 24.3 & 25.0 & 33.8 & 0.854 & 0.018 \\
\hline Vegetables & 31.5 & 81.2 & 37.5 & NA & 47.4 & $0.022 *$ & 0.156 \\
\hline Tobacco & NA & 22.0 & 19.7 & NA & 20.6 & 0.290 & 0.123 \\
\hline Mean & 45.3 & 48.6 & 46.9 & 37.7 & 46.2 & & \\
\hline
\end{tabular}

Note: $\alpha=* * *$ is significant at $0.1 \%, * *=$ significant at $1 \%, *=$ significant at $5 \%$, NS $=$ not significant.

level, which is additionally supported by the highest rainfall level when compared to other villages in the studied area. However, the demographic pressure for agricultural intensification seems to be also present in Matondovela, with a much lower rainfall level. It is also relevant to note that agricultural intensity seems to increase with population size in a much less than proportional way, suggesting that technology is constraining intensification. In contrast, in the three villages with lower rainfall (rain $<1120 \mathrm{~mm}$ ), the agricultural intensity seems to be more constrained by insufficient water than promoted by population growth.

\subsection{Proportion of agricultural output lost to crop raiding}

Table 7 presents the average proportion of agricultural output perceived to be lost to crop raiding for each crop and FS with the results of the ANOVA across FS at the farm level. Overall losses were about $46 \%$ of the total expected production. The highest losses correspond to cowpea (62\%) and pea (58\%), and the lowest to tobacco (21\%) and sweet potato (34\%). The highest price is also related to the highest crop loss (See Table 7 and Appendix B) and less output sold (Appendix D). The Specialized Rice FS recorded the heaviest average level of loss, almost half of total expected production, while the Specialized Sorghum FS was the one with the lightest average losses (38\%). Vegetables (81 $\%$ ) followed by pea $(72 \%)$ were the most raided crops in the Specialized Rice FS. Cowpea (57 \%) and rice (49\%) were the most raided crops in the Specialized Sorghum FS. The Specialized Maize FS lost more cowpea $(60 \%)$ and sweet potato (53 \%) than other crops, while the Mixed Crops FS lost more cowpea (65\%) and pea $(63.2 \%)$. The proportion of output lost varied significantly across FS for some crops such as maize and vegetables.

3.4.1. Pattern of losses to crop raiding across villages and its relation to LFS, potential and actual damage, and protective measures

Table 8 presents the disposition of LS and FS across villages, the levels of potential and actual damages, average losses and the availability of electric fence at the village level. The highest overall losses occurred in Macalange (66 \%) and Mucoria (53\%), while the lowest losses occurred in Mbamba (35 \%) and Naulala (39\%). 
Table 8

Pattern of losses to crop raiding across villages and its relation to LFS, potential and actual damage and protective measures.

\begin{tabular}{|c|c|c|c|c|c|c|c|}
\hline \multirow[b]{2}{*}{ Villages } & \multicolumn{2}{|l|}{ SYSTEMS } & \multicolumn{2}{|c|}{ POTENTIAL DAMAGE } & \multirow[b]{2}{*}{ Actual damage } & \multirow[b]{2}{*}{ Losses (\%) } & \multirow[b]{2}{*}{ Fence } \\
\hline & Livelihood & Farming & Crop Raiding (1) & Crop Raiding (2) & & & \\
\hline Chamba & $\longrightarrow$ & Maize \& Rice & Medium & Medium & Medium & 43.6 & No \\
\hline Macalange & $\longrightarrow$ & Rice & Medium & High & High & 66.0 & No \\
\hline Matondovela & $\longrightarrow$ & Maize & High & High & Medium & 42.6 & No \\
\hline Mbamba & Gatherers & Mixed \& Sorghum & High & High & Low & 34.8 & Yes \\
\hline Mecula & Employees & - & Low & Medium & Medium & 48.2 & No \\
\hline Mucoria & Hunters & Mixed & Medium & Medium & High & 53.1 & No \\
\hline Naulala & Gatherers & Sorghum & High & High & Low & 39.3 & Yes \\
\hline
\end{tabular}

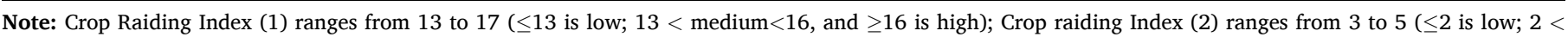
medium $<4$, and $\geq 5$ is high); Actual damage, ranges from $35 \%$ to $66 \%$ ( $\leq 40 \%$ is low; $40 \%<$ medium $<50 \%$, and $\geq 50 \%$ is high).

Crop Raiding index (1) ranged from low to high, whereas Crop Raiding Index (2) varied from medium to high. Actual damage ranged from low to medium. Gatherers, which are mostly specialized in Sorghum, are located in Mbamba and Naulala villages and are generally characterized by having high potential damage for both Crop Raiding Indexes, while the actual damage is low. Interestingly, both villages have fenced crop fields. Specialized Maize and Rice are mostly located in Chamba, Macalange, and Matondovela villages. In these villages, actual and potential damage varies from medium to high, and none are fenced. In Mucoria village, where most of the households are Hunters, mixed FS is the most predominant. Despite medium potential damage for both crop raiding indexes, the actual damage is high, and the agricultural fields are not fenced.

It was not possible to establish multivariate models that account for the main drivers of these significant losses across FS and villages, despite some efforts in that direction. In the discussion section, we address possible causes for this limitation in an exploratory way and identify several hypotheses that require more data to be tested.

\section{Discussion}

The three crops that characterize the Specialized FS (maize, rice and sorghum) are also reported to be an important component of all FS in the all study area, regardless of our cluster classification. Maize is regarded as the dominant and most widespread crop, not only in this area (MAE, 2005) but also in all northern and central Mozambique (Dixon, 2019). Likewise, in our FS study, maize is amongst the top two most important crops, accounting for $20 \%$ of agricultural production, even in the specialized sorghum, the one FS with lowest proportion of maize.

Employees are clearly the only LS category that does not directly depend on either agriculture or NTFPs harvesting. Farmers showed the least gathering effort, followed by Hunters. We would expect to detect an association between specialized FS and the Farmers LS, but this was not possible, which indicates that specialization within farming does not necessarily mean that the household doesn't depend on harvesting NTFPs. In fact, even in the specialized FS some households heavily rely on NTFPs to cope with their daily needs. This dependence is also well documented in almost all rural villages and PAs of DCs (Jew et al., 2019; Smith et al., 2017; Bruschi et al., 2011, 2014). For instance, firewood and charcoal are the main sources of energy provision for cooking and heating in African rural and urban areas (Baumert et al., 2016; Vollmer et al., 2017; Woollen et al., 2016; Felix, 2015; Ryan et al., 2016). Likewise, in our LS, firewood proved to be the most important NTFP, based on harvest effort. Bushmeat and traditional medicines are also in great demand in the NNR, but not necessarily in the same proportion as firewood.

Hunters and Farmers together accounted for over $90 \%$ of all households, possibly because the abundance and proximity to NTFPs may lead the household to underreport the effort they commit to harvesting NTFPs, since it is also widespread practice to delegated to young people or carried out by opportunistic harvesting while returning from agricultural fields or water collection. The strong communal relationships that characterized most of the rural areas of DCs, with open shared space for the collection of provisioning ecosystem services, especially traditional medicine and firewood (Boafo et al., 2016), which were not documented here in the respondents' answers. However, we are confident that it did not affect our results, as we were more interested in the time/effort that households spend to collect NTFPs, as an alternative for labour used in agriculture.

\subsection{Interpreting LFS choice and its relationships with agriculture intensification}

Based on the estimated Multinomial Logistic Regression Models, LS were driven by socio-economic variables measured at the household level, whereas FS were driven by biophysical variables measured at the village level. This suggests that biophysical constraints, which are mostly out of the households' control, underlie the decision of adopting one FS over another. In contrast, LS choice, while responding to household-level variables, seems to be related to the prevalent FS option at the village level. For example, Hunters and Gatherers are mainly located in the Mbamba and Naulala villages, where the dominants FS are the Mixed and Specialized Sorghum FS. The Specialized Sorghum FS has, on average, a relatively low agricultural output. In addition, it appears to be the poorest FS, as regards both cash crops, the proportion of the crop sold and nutrition value. This suggests that Specialized Sorghum farmers have intensified gathering effort to offset the nutrition gap and low agricultural productivity. This low productivity is probably related to biophysical constraints (lower rainfall) and fear of crop raiding (high potential for damage). Thus, by adopting the Mixed or the Specialized Sorghum FS and by intensifying hunting and gathering effort, households appear to have developed a clear strategy to deal with these constraints, which probably occurred before the assistance of the private NGO's (Chuilexi and Luwire Conservancy and Niassa Carnivore Project), with their fencing programmes, which reduced actual damage. According to Ho et al. (2017), agricultural intensification requires vast arable land and technology which are not available in the NNR, not only because of its higher costs of acquisition, diffusion, and adoption, but also because they could have negative environmental and conservation implications, which would not be allowed by the reserve management.

Although both rainfall and availability of flatland are important drivers for the choice of the specialized rice FS, increase in flatland has a stronger effect than rainfall, due to the limiting availability of flatland in the reserve. In fact, the proportion of flatland (slope $<2 \%$ ), ranged from 9.7\%-33.4\% (average of $19 \%$ ). This is even more challenging for traditional rice production that, in addition to flatland, requires wetlands (Dixon, 2019). With increasing population in the reserve, requiring more land for agriculture, the availability and accessibility of land will be an even stronger constraint in the future. Regardless of the FS type, intensification appears to be driven by population size (Fig. 2), an effect that is less clear in drier areas, where rainfall is a strong constraint for intensification.

For all FS, future intensification could be seen as a strategy to deal with population growth in the reserve, by reducing the likely raises in 
Table B1

Average selling price for each crop declared by households.

\begin{tabular}{lll}
\hline $\mathrm{N}^{\mathrm{o}}$ & Crops & Average Price (MZN/Kg) \\
\hline 1 & Maize & 31.00 \\
2 & Shelled Peanut & 32.61 \\
3 & Dried Cassava & 18.35 \\
4 & Shelled Rice & 41.70 \\
5 & Cowpea & 66.57 \\
6 & Pea & 62.37 \\
7 & Sorghum & 40.59 \\
8 & Millet & 61.21 \\
9 & Sesame & 79.22 \\
10 & Sweet potato & 26.10 \\
11 & Vegetables & 31.38 \\
12 & Tobacco* & 315.91 \\
13 & Honey* & 95.00 \\
14 & Fish & 85.71 \\
\hline
\end{tabular}

* The price of honey is giving in liters while tobacco is giving in a roll.

land pressure in the reserve and so saving more land for natural habitats. Our results suggest, according to the literature, this strategy will be easier to adopt in areas with higher rainfall and flatter lands. Our results also suggest that increases in gathering effort may be interpreted as a response to low agricultural productivity (Tables 3 and 8). This interpretation would be consistent with our finding of a negative association between the size of the household and the choice of a non-Farmer LS.
Contrary to what we expected (at least, based on the Multinomial Logistic Regression), the Mixed Crop FS was seemingly driven by population growth due to the following possible reasons: (i) markets are virtually non-existent in the NNR, so households need to diversify their production for consumption and sharing; (ii) the Mixed Crop FS occurs in agro-ecological zones where biophysical conditions are not favourable to maize or rice specialization and/or there is a high potential and/ or actual damage due to crop raiding (as is depicted in Fig. 2 and Table 8) and (iii) most conservation NGO's (Chuilexi Conservancy and Niassa Carnivore Project) that developed capacity-building for the local people to improve their agriculture production techniques, business assistance (including credits) and scholarship for their children are confined to Mbamba and Naulala villages. Thus, a considerable number of household probably moved to these villages to catch up with those benefits.

\subsection{Incipient markets, diversification of LFS and its implications for food security in $P A$ with high crop raiding levels}

All FS in the reserve (including the Specialized ones) are fairly diversified. This is typical of rural and remote areas of miombo, where the connections to external markets are very limited. Hence, households need to diversify their FS and embrace other off-farm practices to cope with all food needs (Jew et al., 2019). Even though market access is insignificant in the NNR, there are some cash crops such as tobacco and

Table C1

Total Expected Production (TEP), per crop in each farming System in Metical (MZN).

\begin{tabular}{|c|c|c|c|c|c|c|c|}
\hline Crops & $\begin{array}{l}\text { Specialized Maize } \\
93(28.79)\end{array}$ & $\begin{array}{l}\text { Specialized Rice } \\
80(24.77)\end{array}$ & $\begin{array}{l}\text { Mixed FS } \\
128(39.63)\end{array}$ & $\begin{array}{l}\text { Specialized Sorghum } \\
22(6.81)\end{array}$ & $\begin{array}{l}\text { Total } \\
323(100)\end{array}$ & Alf $(\alpha)$ & $\mathrm{Eta}^{2}$ \\
\hline Maize & 24278.89 & 9898.96 & 7673.91 & 7154.85 & 12970.66 & $0.000^{* * *}$ & 0.169 \\
\hline Peanut & 322.61 & 878.88 & 3217.34 & 1852.93 & 1711.76 & $0.000^{* * *}$ & 0.108 \\
\hline Cassava & 1364.76 & 1498.70 & 1129.76 & 567.08 & 1250.48 & $0.584^{\mathrm{NS}}$ & 0.006 \\
\hline Rice & 4516.41 & 14589.44 & 2697.89 & 2968.74 & 6185.21 & $0.000 * * *$ & 0.228 \\
\hline Cowpea & 575.47 & 510.06 & 3034.46 & 423.60 & 1523.38 & $0.000^{* * * *}$ & 0.060 \\
\hline Pea & 572.70 & 661.86 & 1187.89 & 725.72 & 849.00 & $0.201^{\mathrm{NS}}$ & 0.014 \\
\hline Sorghum & 611.49 & 1079.23 & 2676.51 & 19805.03 & 2852.98 & $0.000 * * *$ & 0.357 \\
\hline Millet & 32.93 & 65.06 & 350.77 & 167.07 & 175.98 & $0.001^{* *}$ & 0.049 \\
\hline Sesame & 591.21 & 1576.59 & 2008.49 & 489.76 & 1390.00 & $0.122^{\mathrm{NS}}$ & 0.018 \\
\hline Sweet potato & 337.35 & 368.72 & 614.80 & 94.76 & 438.55 & $0.586^{\mathrm{NS}}$ & 0.006 \\
\hline Vegetables & 529.06 & 749.18 & 975.70 & 0.00 & 724.54 & $0.522^{\mathrm{NS}}$ & 0.007 \\
\hline Tobacco & 0.00 & 1492.67 & 1466.02 & 0.00 & 950.66 & $0.224^{\mathrm{NS}}$ & 0.014 \\
\hline Total & 33732.89 & 33369.36 & 27033.53 & 34249.54 & 31023.19 & & \\
\hline
\end{tabular}

Note: Number in the brackets is the percentage of household interviewed per villages.

$\alpha=* * *$ is significant at $0.1 \%, * *=$ significant at $1 \%, *=$ significant at $5 \%, \mathrm{NS}=$ not significant.

Table D1

Gross revenue from the Total Crop Sold (TCS) per crop in each farming System in Metical (MZN).

\begin{tabular}{|c|c|c|c|c|c|c|c|}
\hline Crops & $\begin{array}{l}\text { Specialized Maize } \\
93(28.79)\end{array}$ & $\begin{array}{l}\text { Specialized Rice } \\
80(24.77)\end{array}$ & $\begin{array}{l}\text { Mixed FS } \\
128(39.63)\end{array}$ & $\begin{array}{l}\text { Specialized Sorghum } \\
22(6.81)\end{array}$ & $\begin{array}{l}\text { Total } \\
323(100 \%)\end{array}$ & Alf $(\alpha)$ & $\mathrm{Eta}^{2}$ \\
\hline Maize & 5257.23 & 1298.51 & 845.58 & 1300.63 & 2258.98 & $0.000^{* * *}$ & 0.095 \\
\hline Peanut & 39.62 & 140.23 & 640.51 & 355.76 & 324.20 & $0.002^{* *}$ & 0.045 \\
\hline Cassava & 110.48 & 224.75 & 129.00 & 33.36 & 140.87 & $0.684^{\mathrm{NS}}$ & 0.005 \\
\hline Rice & 652.95 & 2335.56 & 364.93 & 405.69 & 938.72 & $0.000^{* * *}$ & 0.060 \\
\hline Cowpea & 0.00 & 24.96 & 293.30 & 0.00 & 122.41 & $0.056^{\mathrm{NS}}$ & 0.023 \\
\hline Pea & 198.50 & 35.86 & 82.83 & 141.74 & 108.51 & $0.659^{\mathrm{NS}}$ & 0.005 \\
\hline Sorghum & 22.70 & 101.48 & 296.19 & 2996.40 & 353.13 & $0.000^{* * * *}$ & 0.124 \\
\hline Millet & 0.00 & 30.60 & 38.26 & 0.00 & 22.74 & $0.542^{\mathrm{NS}}$ & 0.007 \\
\hline Sesame & 315.20 & 796.22 & 639.99 & 360.12 & 566.11 & $0.620^{\mathrm{NS}}$ & 0.006 \\
\hline Sweet potato & 36.43 & 84.69 & 307.40 & 0.00 & 153.28 & $0.512^{\mathrm{NS}}$ & 0.007 \\
\hline Vegetables & 269.59 & 88.65 & 443.72 & 0.00 & 275.42 & $0.498^{\mathrm{NS}}$ & 0.007 \\
\hline Tobacco & 0.00 & 1164.91 & 1172.32 & 0.00 & 753.10 & $0.223^{\mathrm{NS}}$ & 0.014 \\
\hline Honey & 117.73 & 190.41 & 732.63 & 908.77 & 433.28 & $0.018^{*}$ & 0.031 \\
\hline Fish & 215.19 & 600.38 & 291.85 & 0.00 & 326.32 & $0.625^{\mathrm{NS}}$ & 0.005 \\
\hline Total & 7235.61 & 7117.20 & 6278.52 & 6502.46 & & & \\
\hline
\end{tabular}

Note: Number in the brackets is the percentage of household interviewed per villages.

$\alpha=* * *$ is significant at $0.1 \%, * *=$ significant at $1 \%, *=$ significant at $5 \%, \mathrm{NS}=$ not significant. 
Table E1

Proportion (\%) of total crop harvested that was sold (PCS) In each farming System in percentage (\%).

\begin{tabular}{llllll}
\hline & $\begin{array}{l}\text { Specialized } \\
\text { Maize }\end{array}$ & $\begin{array}{l}\text { Specialized } \\
\text { Rice }\end{array}$ & $\begin{array}{l}\text { Mixed } \\
\text { FS }\end{array}$ & $\begin{array}{l}\text { Specialized } \\
\text { Sorghum }\end{array}$ & Total \\
& $93(28.79)$ & $80(24.77)$ & $\begin{array}{l}128 \\
(39.63)\end{array}$ & $22(6.81)$ & 323 \\
& & & & $(100$ \\
& & & & $\%)$ \\
\hline Maize & 39.8 & 26.6 & 21.0 & 29.3 & 32.7 \\
Peanut & 25.2 & 25.9 & 34.6 & 25.3 & 32.2 \\
Cassava & 15.9 & 23.8 & 19.2 & 10.0 & 19.5 \\
Rice & 26.4 & 33.8 & 28.4 & 26.6 & 30.9 \\
Cowpea & 0.0 & 9.1 & 27.3 & 0.0 & 21.4 \\
Pea & 52.5 & 19.4 & 18.9 & 35.7 & 30.6 \\
Sorghum & 6.7 & 13.7 & 20.3 & 24.2 & 20.7 \\
Millet & 0.0 & 47.1 & 10.9 & 0.0 & 12.9 \\
Sesame & 74.9 & 72.6 & 54.4 & 86.2 & 63.8 \\
Sweet & 23.1 & 37.6 & 66.1 & 0.0 & 52.8 \\
$\quad$ potato & & & & & \\
Vegetables & 74.4 & 62.8 & 72.7 & 0.0 & 72.3 \\
Tobacco & 0.0 & 100.0 & 99.6 & 0.0 & 99.7 \\
Honey & 100.0 & 100.0 & 100.0 & 100.0 & 100.0 \\
Fish & 100.0 & 100.0 & 100.0 & 0.0 & 100.0 \\
Total & 38.5 & 39.7 & 40.2 & 29.2 & 38.6 \\
\hline
\end{tabular}

sesame, and some partly commercial honey and fish-related activities (see Appendixes B, D and E). In which case the production appears to be market-oriented since more than $60 \%$ of the output was sold. In addition, these crops and products are among the least raided by wildlife. Thus, we suggest that households have adopted these less-raided crops for sale, and by doing so, overcome income shocks and food shortage due to crop raiding. Furthermore, most specialized farming systems are linked to high price volatility (Dixon et al., 2001). We have also noticed that, for those "pivotal" crops that best describe FS (maize, rice and sorghum), there is also a set of secondary crops (cassava and millet) widespread through all FS. This alternate production plan (primary and secondary crop) is probably aimed at diversifying the risk of crop raiding, climate, market and other unpredictable risks. In fact, there is empirical evidence that agriculture diversification in smallholder farms is a response to nature and market shocks (Ho et al., 2017; Sraïri and Ghabiyel, 2017).

Hunters are mostly located in Mucoria village, where actual crop damage was high (Table 8). This can be interpreted either as an adaptive response or the result of retaliatory killing of provocative crop raiders (Moreto, 2019). The abundance of wild animals in this village seems to increases the likelihood of HWC, as mentioned by Baral and Heinen (2007). Data from the NCP (2018) report 953 incidents of livestock depredation between 2017 and 2018, which represent $11.11 \%$ of all HWC events in the NNR.

\subsection{The Livelihood and Farming System approach: implications for intervention strategies to improve nature conservation and sustainable development in PAs of DCs}

The results of this research led us to identify a set of 6 policies/incentives that are implicit in the previous discussions, but that need to be outlined in a more explicit manner to contribute for the re-framing of conservation narratives towards a sustainable development of people living inside PAs of DCs, whose livelihoods need to be improved.

First, we have demonstrated that employees are, on average, younger, better educated and more wealthy than other LS, and are not or minimally dependent on agriculture or NTFP harvesting. Thus, training and equipping local people with new skills to reduce their dependence on farming, gathering and hunting (e.g. rangers, touristic guides, teachers, etc), and investing in conservation activities such as sustainable tourism and eco-tourism to employ these people, would lower the harvesting effort and agricultural expansion as well as change their LFS towards lower impact levels. Second, Mixed and Specialized Sorghum FS appear to have evolved as a response to crop raiding, biophysical constraints, lack of market, income and food requirements. Diversifying FS (e.g. growth of cash crops and less palatable crops), in addition to smallscale off-farm activities (e.g. hunting and harvesting of NTFPs), can raise incomes and reduce the risk of households falling into food insecurity due to crop raiding, agricultural pests, diseases and climate hazzards.

Third, in general, all FS in the NNR, especially the Mixed and Specialized Sorghum FS, appear to be struggling with poor soils, lack of fertilizer as well as insufficient water availability. Improving agriculture practices by implementing conservation agriculture, such as green manure, crop rotation, intercropping, coppicing trees, mulching and traditional soil/water conservation (Bayala et al., 2012) may significantly raise crop yields, simultaneously reducing food insecurity and enhancing environmental services and the resilience of agro-ecosystems (Ajayi et al., 2011). Conservation-friendly agricultural practices, such as parkland trees, soil water conservation and mulching, have provided impressive results in arid zones with poor soils (Bayala et al., 2012), as is the case of areas in the NNR where the Specialized Sorghum and Mixed FS are predominant. The Niassa Carnivore Project (NCP, 2017) has been working with 19 local farmers in the Mbamba village, in a similar conservation agriculture project (e.g. testing methods of natural manure and mixed cropping), to improve soil nutrition and agricultural yields. This project has achieved considerable success in this pilot phase, which can be replicated throughout the whole reserve in the future. Fourth, improving agriculture and livestock practices by assisting local households with drought resistant seeds and livestock breeding resistant to diseases, such as trypanosomosis, as well as helping local people with other protein sources such as poultry breeding will likely reduce unsustainable bushmeat hunting; The Niassa Carnivore Project (NCP, 2017) is also an example of good practice in this respect.

Fifth, the transition from peasant livelihood strategies to specialized or diversified strategies is mainly influenced by natural assets, human assets, social and informational assets (Yang et al., 2018). Therefore, we suggest that central governments, in partnership with PA administrations and NGO managers, should identify agro-ecological zones with better conditions for agricultural intensification, invest in road and agricultural infrastructure and reallocating people to these areas may be a solution to overcome biophysical constraints and lack of market access. This would also reduce drastically the costs of assisting local people (e.g. capacity building in conservation agriculture and business entrepreneurship), regulating some illegal activities, such as bushmeat hunting and harvesting NTFPs, as well as improving wildlife corridors. At the present time, the way that the communities are so widely dispersed throughout the reserve (approximately 42 villages), with poor road infrastructure and lack of essential services, does not help to implement conservation and development policies. With the rapid growth of the human population within the reserve, which is expected to reach 200, 000 people in 2050 under a "business as usual scenario", no conservation policy/strategy can act effectively without this spatial planning approach.

Last but not the least, enforce PA management standards in the DCs would require to set management principles supporting the sustainable development of PA residents, promoting changes in LFS according to the proposals made above, and that could promote sustainable development through the certification of PAs as sustainable destinations for ecotourism. Implementation of these actions may require long-term collaboration and commitment among all stakeholders involved in conservation in the NNR and other PA of DC. More important, it will first need empowerment and transparent involvement of local people who bear the costs of conservation in the NNR (Mbanze et al., 2019b). Effective participation of local people in conservation requires, first, capacity-building, education and awareness.

We have exemplified in the NNR how classifying households by LFS and using Multiple Linear Model to identify the drivers of LFS choice may provide an analytical framework to discuss policies aimed to improve conservation in the NNR and other PAs in DCs. This framework 
includes a combination of LFS that can be implemented to enhance biodiversity and ecosystem services provisioning. This combination of LFS has a potential to reduce HWC, while improving the income and livelihood of local households, thus enhancing conservation-friendly behaviour and increasing ecosystem resilience and adaptability to climate hazards. Here we offer a novel and detailed evidence-based framework that can be used to improve conservation in the NNR and in other PAs in DCs elsewhere. Its implementation depends on all stakeholders involved in conservation to understand the material or intangible benefits that can result from each action. However, we believe that conservation managers, donors and decision-makers are in the best position to ensure the implementation of the present proposed framework.

\section{Conclusions}

Based on the survey results, four different LFS were identified in the NNR. The choice of LS is driven by socio-economic factors at the household level, more specifically, the household size and the level of education of the household. Employees, who are well educated, are on average wealthier than the other LS we recognized. Gatherers exhibit the highest level of gathering effort and are primarily located in Mbamba and Naulala. Their FS are predominantly Specialized in Sorghum and Mixed FS, in which expansion and specialization are constrained by biophysical conditions (low rainfall and low availability of flatland). The Specialized maize and rice FS are located in areas with better biophysical conditions, thus allowing intensification and specialization of FS. This intensification appears to be induced by larger household sizes, allowing both agricultural and off-farm activities. However, production in these FS is constrained by higher crop damage by raiding animals.

Households in almost all LFS (except employees) appear to be struggling to cope with their basic needs. Since these FS can be considered an integral part of the conservation area, the required improvement does not necessarily require abrupt changes and can be done through multiple, complementary measures. The most important measures that can be outlined from this research are: (i) provide capacity-building for local people to enhance farming activities, so that they can improve their income and livelihood, hence reducing pressure on the land and ecosystem services; (ii) improve their FS (e.g. improved and drought-resistant seeds and conservation agriculture); (iii) implementing mixed FS with cash crops that are subject to less crop raiding and are less sensitive to drought and other climate constraints; (iv) synchronizing FS activities with other important off-farm occupations and training local people in the adoption of effective, sustainable ways to reduce crop raiding.

\section{Declaration of Competing Interest}

The authors report no declarations of interest.

\section{Acknowledgements}

The authors acknowledge all institutions and individuals who directly and indirectly supported this research. We especially acknowledge the following institution: Niassa National Reserve Administration, Serviço Distrital de Actividades Económicas-SDAE in Mecula and the Niassa Carnivore Project. We thank all field assistants (Amade M. Mário, Cely Mendes, Quitéria Muarapaz, Lério Carlos H. Mutecomala and Nildo Paulo) and the villages and households that took part in the survey. Robert K. Colwell and Sophie Calmé, mentors of the first author at Association for Tropical Biology and Conservation (ATBC), and Paula Alves, provided English revision and some important inputs. We also acknowledge the Editor-in-Chief, the managing editor and the anonymous reviewers for providing valuable insights to improve the quality of the manuscript. World Wildlife Fund for Nature (WWF), Russell E. Training Education for Nature Program, provided grant contract \#RF37, for field data collection; Fundação para Ciência e Tecnologia (FCT) of Portugal, provided the scholarship of the first author (Ref $n^{\circ}$ SFRH/BD/ 113955/2015).

\section{Appendix A}

A Survey to the household in the Niassa National Reserve

\section{General information}

a) Name of the interviewer

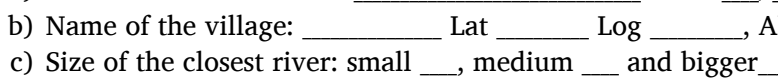
Date:

d) For how long are you living in the reserve? I was born here __.; $>10$ year__; 5-10 years __; $<5$ years __

\section{Socio-economic information of the respondent}

a) Name (not compulsory)

b) Gender Male $\square$ Female $\square$

c) Number of people in the household

d) Number of workers in the household

\begin{tabular}{|c|c|c|c|c|c|}
\hline $\mathrm{N}^{\circ}$ & kinship degree & Age & Occupation & Income & School \\
\hline a) & Household & - & - & - & 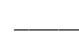 \\
\hline b) & & - & & - & \\
\hline c) & 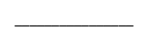 & 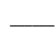 & & & \\
\hline d) & $\bar{L}$ & $\overline{-}$ & 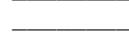 & 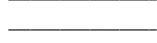 & \\
\hline e) & & 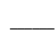 & & & \\
\hline f) & 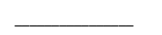 & 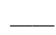 & & 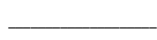 & 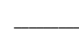 \\
\hline g) & 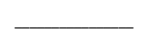 & 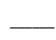 & 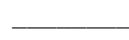 & 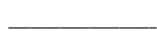 & 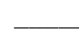 \\
\hline h) & 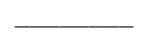 & 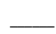 & 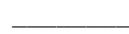 & 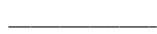 & \\
\hline
\end{tabular}




\section{Farming information}

Below is the list of most common crops in the NNR. For those that you have planted in the last season, could you please provide total amount harvested, consumption, losses for crop raiders, quantity sold and its respective price

\begin{tabular}{|c|c|c|c|c|c|c|}
\hline $\mathrm{N}^{\mathrm{o}}$ & Crop & Harvested (Kg) & Lost (Kg) & Consumption (Kg) & Sold (Kg) & Price (MZN) \\
\hline a) & Maize & & - & _ & - & \\
\hline b) & Peanut & & & & & \\
\hline c) & Cassava & & & & & \\
\hline d) & Rice & & & 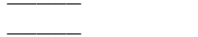 & & \\
\hline e) & Cowpea & & & & & \\
\hline f) & Pea & & & & & \\
\hline g) & Sorghum & $\bar{Y}$ & 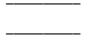 & 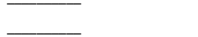 & & \\
\hline h) & Millet & , & 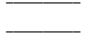 & 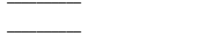 & 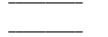 & \\
\hline i) & Sesame & & & & & \\
\hline j) & Sweet potato & 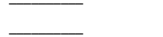 & 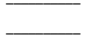 & 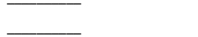 & & \\
\hline 1) & Vegetables* & 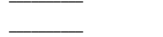 & 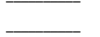 & 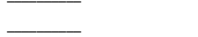 & 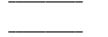 & ए \\
\hline m) & Tobacco* & $\overline{ }$ & $\overline{-}$ & $\bar{\square}$ & $\bar{\square}$ & \\
\hline
\end{tabular}

Note: all products are measured in 20 litters plastic containers, except those marked to asterisks.

Vegetable was measured in a big open plastic basket or sachets of 100 litter while tobacco is measures rolls of 2 Kgs. Prices a given for each unity of measurement which was converted for $\mathrm{Kg} / \mathrm{MZN}$.

3.1 Could you please rank the top four most important crop raiding that have raided you farm and the most important crops each animal prefers

\section{Harvesting of non-timber products}

Mark all products and materials that you harvest from the forest, rivers, soils, etc. The frequency of harvest, quantities the final purpose and its price if you sell.

\begin{tabular}{|c|c|c|c|c|c|}
\hline $\mathrm{N}^{\mathrm{o}}$ & Products & Frequency of harvesting & Propose & Quantities kg/liters & Price (MZN) \\
\hline a) & Medicines (roots, leaves, branches and fruits) & day _, week_, month_, semester_year_ & sell _, use _ & 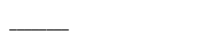 & 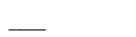 \\
\hline b) & Grass & day _, week_, month_, semester_year_ & sell_, use _ & & {[} \\
\hline c) & Stakes & day _, week_, month_, semester_year_ & sell _, use _ & & - \\
\hline d) & Bamboos & day _, week_, month_, semester_year_ & sell _, use _ & & 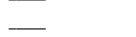 \\
\hline e) & Firewood & day _, week_, month_, semester_year_ & sell_, use _ & & {[} \\
\hline f) & Ropes & day _, week_, month_, semester_year_ & sell _, use & & - \\
\hline g) & Honey* & day_, week_, month_, semester_year_ & sell _, use _ & + & 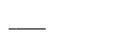 \\
\hline h) & Fish\# & day _, week _, month_, semester_year_ & sell_, use _ & & 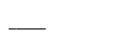 \\
\hline i) & Insects & day _, week_, month_, semester_year_ & sell _, use _ & 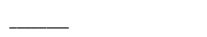 & - \\
\hline j) & Bush meat & day _, week_, month_, semester_year_ & sell _, use _ & $\overline{-}$ & - \\
\hline 1) & Others & day _, week_, month_, semester_year_ & sell _, use _ & 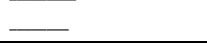 & $\overline{-}$ \\
\hline
\end{tabular}

*Honey was measured in litters.

\#Fish in plastics containers of $20 \mathrm{~kg}$.

See Table B1, Table C1, Table D1, Table E1.

\section{Appendix B. Supplementary data}

Supplementary material related to this article can be found, in the online version, at doi:https://doi.org/10.1016/j.landusepol.2020.105056.

\section{References}

Ajayi, O.C., Place, F., Akinnifesi, F.K., Sileshi, G.W., 2011. Agricultural success from Africa: the case of fertilizer tree systems in southern Africa (Malawi, Tanzania, Mozambique, Zambia and Zimbabwe). Int. J. Agric. Sustain. 9, 129-136. https://doi. org/10.3763/ijas.2010.0554.

Alemayehu, M., Beuving, J., Ruben, R., 2018. Risk preferences and farmers' livelihood strategies: a case study from Eastern Ethiopia. J. Int. Dev. 30, 1369-1391. https:// doi.org/10.1002/jid.3341.

ANAC, 2016. Plano Estratégico da Administração Nacional das Áreas de Conservação. Maputo.

Auty, H., Morrison, L.J., Torr, S.J., Lord, J., 2016. Transmission dynamics of rhodesian sleeping sickness at the interface of wildlife and livestock areas. Trends Parasitol. 32, 608-621. https://doi.org/10.1016/j.pt.2016.05.003.

Baral, N., Heinen, J.T., 2007. Resources use, conservation attitudes, management intervention and park-people relations in the Western Terai landscape of Nepal. Environ. Conserv. 34, 64-72. https://doi.org/10.1017/S0376892907003670.

Bartlett, J.E., Kotrlik, J.W., Higgins, C.C., 2001. Organizational Research : Determining Appropriate Sample Size in Survey Research, 19, pp. 43-50.

Baumert, S., Luz, A.C., Fisher, J., Vollmer, F., Ryan, C.M., Patenaude, G., ZorrillaMiras, P., Artur, L., Nhantumbo, I., Macqueen, D., 2016. Charcoal supply chains from Mabalane to Maputo: who benefits? Energy Sustain. Dev. 33, 129-138. https://doi. org/10.1016/j.esd.2016.06.003.
Bayala, J., Sileshi, G.W., Coe, R., Kalinganire, A., Tchoundjeu, Z., Sinclair, F., Garrity, D., 2012. Cereal yield response to conservation agriculture practices in drylands of West Africa: a quantitative synthesis. J. Arid Environ. 78, 13-25. https://doi.org/ 10.1016/j.jaridenv.2011.10.011.

Beale, C.M., Van Rensberg, S., Bond, W.J., Coughenour, M., Fynn, R., Gaylard, A. Grant, R., Harris, B., Jones, T., Mduma, S., Owen-Smith, N., Sinclair, A.R.E., 2013. Ten lessons for the conservation of African savannah ecosystems. Biol. Conserv. 167, 224-232. https://doi.org/10.1016/j.biocon.2013.08.025.

Bieber-Klemm, S., Martinez, S., Kissling, I., Schmill, J., Jacob, A., 2006. Access and benefit sharing. Good practice for academic research on genetic resources. Biodivers. Sci. Bern. 1-61. https://doi.org/10.1360/biodiv.070167.

Bluwstein, J., Lund, J.F., 2016. Territoriality by conservation in the Selous-Niassa Corridor in Tanzania. World Dev. https://doi.org/10.1016/j.worlddev.2016.09.010 $\mathrm{XX}$.

Boafo, Y.A., Saito, O., Jasaw, G.S., Otsuki, K., Takeuchi, K., 2016. Provisioning ecosystem services-sharing as a coping and adaptation strategy among rural communities in Ghana's semi-arid ecosystem. Ecosyst. Serv. 19, 92-102. https://doi.org/10.1016/j. ecoser.2016.05.002.

Booth, Vernon R., Dunham, K.M., 2014. Elephant poaching in Niassa Reserve, Mozambique: population impact revealed by combined survey trends for live elephants and carcasses. Oryx 1-10. https://doi.org/10.1017/S0030605314000568.

Brennan, A.J., Kalsi, J.K., 2015. Elephant poaching \& ivory trafficking problems in SubSaharan Africa: an application of O'Hara's principles of political economy. Ecol. Econ. 120, 312-337. https://doi.org/10.1016/j.ecolecon.2015.08.013. 
Brister, E., 2016. Disciplinary capture and epistemological obstacles to interdisciplinary research: lessons from central African conservation disputes. Stud. Hist. Philos. Sci. Part C Stud. Hist. Philos. Biol. Biomed. Sci. 56, 82-91. https://doi.org/10.1016/j. shpsc.2015.11.001.

Bruschi, P., Morganti, M., Mancini, M., Signorini, M.A., 2011. Traditional healers and laypeople: a qualitative and quantitative approach to local knowledge on medicinal plants in Muda (Mozambique). J. Ethnopharmacol. 138, 543-563. https://doi.org/ 10.1016/j.jep.2011.09.055.

Bruschi, P., Mancini, M., Mattioli, E., Morganti, M., Signorini, M.A., 2014. Traditional uses of plants in a rural community of Mozambique and possible links with Miombo degradation and harvesting sustainability. J. Ethnobiol. Ethnomed. 10, 1-22. https://doi.org/10.1186/1746-4269-10-59.

Campbell, B.M., 1996. The Miombo in Transition : Woodlands and Welfare in Africa, Forestry.

Cooney, R., Roe, D., Dublin, H., Phelps, J., Wilkie, D., Keane, A., Travers, H., Skinner, D. Challender, D.W.S., Allan, J.R., Biggs, D., 2017. From poachers to protectors: engaging local communities in solutions to illegal wildlife trade. Conserv. Lett. 10, 367-374. https://doi.org/10.1111/conl.12294.

Dehghani Pour, M., Motiee, N., Barati, A.A., Taheri, F., Azadi, H., Gebrehiwot, K. Lebailly, P., Van Passel, S., Witlox, F., 2017. Impacts of the Hara biosphere reserve on livelihood and welfare in Persian Gulf. Ecol. Econ. 141, 76-86. https://doi.org/ 10.1016/j.ecolecon.2017.05.023.

den Braber, B., Evans, K.L., Oldekop, J.A., 2018. Impact of protected areas on poverty, extreme poverty, and inequality in Nepal. Conserv. Lett. 11, 1-9. https://doi.org/ 10.1111/conl.12576.

Dewees, P.A., Campbell, B.M., Katerere, Y., Sitoe, A., Cunningham, A.B., Angelsen, A., Wunder, S., 2010. Managing the miombo woodlands of Southern Africa: Policies, incentives and options for the rural poor. J. Nat. Resour. Policy Res. 2, 57-73. https://doi.org/10.1080/19390450903350846.

Dickman, A.J., 2010. Complexities of conflict: the importance of considering social factors for effectively resolving human-wildlife conflict. Anim. Conserv. 13, 458-466. https://doi.org/10.1111/j.1469-1795.2010.00368.x.

Dickman, A.J., Hazzah, L., 2015. When wildlife creates problems for the environment and human activities: general features and some case studies. Problematic Wildlife: A Cross-Disciplinary Approach, pp. 107-108. https://doi.org/10.1007/978-3-31922246-2.

Dikgang, J., Muchapondwa, E., 2012. The valuation of biodiversity conservation by the South African Khomani San "bushmen" community. Ecol. Econ. 84, 7-14. https:// doi.org/10.1016/j.ecolecon.2012.09.001.

Dixon, J., 2019. Concept and Classifications of Farming Systems, Encyclopedia of Food Security and Sustainability. Elsevier. https://doi.org/10.1016/b978-0-08-1005965.22155-0.

Dixon, J., Gulliver, A., Gibbon, D., 2001. Farming Systems and Poverty: Improving Farmers' Livelihoods in a Changing Word. FAO and Word Bank. Rome and Washington DC.

Erb, K.H., Haberl, H., Jepsen, M.R., Kuemmerle, T., Lindner, M., Müller, D., Verburg, P. H., Reenberg, A., 2013. A conceptual framework for analysing and measuring landuse intensity. Curr. Opin. Environ. Sustain. 5, 464-470. https://doi.org/10.1016/j. cosust.2013.07.010.

Felix, M., 2015. Future prospect and sustainability of wood fuel resources in Tanzania. Renew. Sustain. Energy Rev. 51, 856-862. https://doi.org/10.1016/j. rser.2015.06.034.

Ferraton, N., Touzard, I., 2009. Comprendre l'agriculture familiale. Diagnostic des systèmes de production. Agricultures tropicales en poche.

Fischer, J., Abson, D.J., Butsic, V., Chappell, M.J., Ekroos, J., Hanspach, J., Kuemmerle, T., Smith, H.G., von Wehrden, H., 2014. Land sparing versus land sharing: moving forward. Conserv. Lett. 7, 149-157. https://doi.org/10.1111/ conl.12084.

Gaillard, J.C., van Niekerk, D., Shoroma, L.B., Coetzee, C., Amirapu, T., 2019. Wildlife hazards and disaster risk reduction. Int. J. Disaster Risk Reduct. 33, 55-63. https:// doi.org/10.1016/j.ijdrr.2018.09.009.

Galvin, K.A., Thornton, P.K., de Pinho, J.R., Sunderland, J., Boone, R.B., 2006. Integrated modeling and its potential for resolving conflicts between conservation and people in the rangelands of East Africa. Hum. Ecol. 34, 155-183. https://doi.org/10.1007/ s10745-006-9012-6.

Game, E.T., Meijaard, E., Sheil, D., Mcdonald-Madden, E., 2014. Conservation in a wicked complex world; challenges and solutions. Conserv. Lett. 7, 271-277. https:// doi.org/10.1111/conl.12050.

Ganzin, N., Poilecot, P., Prin, T., 2010. Vegetation Survey of Niassa National Reserve Oriented for Vegetation Mapping and Range Resources Assessment Using Satellite Imagery.

García-Pérez, Miguel, Núñez-Antón, Vicente, 2003. Cellwise residual analysis in two-way contingency tables. Educ. Psycholog. Meas. 63 (5), 825-839. https://doi.org/ 10.1177/0013164403251280.

Ho, T.Q., Hoang, V.N., Wilson, C., Nguyen, T.T., 2017. Which farming systems are efficient for Vietnamese coffee farmers? Economic Analysis and Policy. Elsevier B.V. https://doi.org/10.1016/j.eap.2017.09.002

Hockings, K.J., McLennan, M.R., 2012. From forest to farm: systematic review of cultivar feeding by chimpanzees - management implications for wildlife in anthropogenic landscapes. PLoS One 7. https://doi.org/10.1371/journal.pone.0033391.

Jew, E.K.K., Dougill, A.J., Sallu, S.M., O'Connell, J., Benton, T.G., 2016. Miombo woodland under threat: consequences for tree diversity and carbon storage. For Ecol. Manage. 361, 144-153. https://doi.org/10.1016/j.foreco.2015.11.011.
Jew, E.K.K., Burdekin, O.J., Dougill, A.J., Sallu, S.M., 2019. Rapid land use change threatens provisioning ecosystem services in miombo woodlands. Nat. Resour. Forum 43, 56-70. https://doi.org/10.1111/1477-8947.12167.

Jorge, A.A., Vanak, A.B.I.T., Thaker, M., Begg, C., Slotow, R.O.B., 2013. Costs and benefits of the presence of leopards to the sport-hunting industry and local communities in niassa national reserve. Mozambique 27, 832-843. https://doi.org/ 10.1111/cobi.12082.

Kramer, D.B., Urquhart, G., Schmitt, K., 2009. Globalization and the connection of remote communities: a review of household effects and their biodiversity implications. Ecol. Econ. 68, 2897-2909. https://doi.org/10.1016/j. ecolecon.2009.06.026.

Krebs, C.J., 2014. Sample size determination and statistical power. Ecological Methodology, pp. 277-321.

Kremen, C., 2015. Reframing the land-sparing/land-sharing debate for biodiversity conservation. Ann. N. Y. Acad. Sci. 1355, 52-76. https://doi.org/10.1111/ nyas. 12845 .

Kuemmerle, T., Erb, K., Meyfroidt, P., Müller, D., Verburg, P.H., Estel, S., Haberl, H., Hostert, P., Jepsen, M.R., Kastner, T., Levers, C., Lindner, M., Plutzar, C., Verkerk, P. J., van der Zanden, E.H., Reenberg, A., 2013. Challenges and opportunities in mapping land use intensity globally. Curr. Opin. Environ. Sustain. 5, 484-493. https://doi.org/10.1016/j.cosust.2013.06.002.

Kuiper, T.R., Loveridge, A.J., Parker, D.M., Johnson, P.J., Hunt, J.E., Stapelkamp, B., Sibanda, L., Macdonald, D.W., 2015. Seasonal herding practices influence predation on domestic stock by African lions along a protected area boundary. Biol. Conserv. 191, 546-554. https://doi.org/10.1016/j.biocon.2015.08.012.

Landry, J., Chirwa, P.W., 2011. Analysis of the potential socio-economic impact of establishing plantation forestry on rural communities in Sanga district, Niassa province, Mozambique. Land Use Policy 28, 542-551. https://doi.org/10.1016/j. landusepol.2010.11.001.

Legendre, P., Legendre, L., 2003. Numerical ecology. In: Developments in Environmental Modelling, Vol. 24, p. 870. https://doi.org/10.1017/CBO9781107415324.004.

Lemessa, D., Hylander, K., Hambäck, P., 2013. Composition of crops and land-use types in relation to crop raiding pattern at different distances from forests. Agric. Ecosyst. Environ. 167, 71-78. https://doi.org/10.1016/j.agee.2012.12.014.

Levers, C., Butsic, V., Verburg, P.H., Müller, D., Kuemmerle, T., 2016. Drivers of changes in agricultural intensity in Europe. Land Use Policy 58, 380-393. https://doi.org/ 10.1016/j.landusepol.2016.08.013.

Lindsey, P.A., Petracca, L.S., Funston, P.J., Bauer, H., Dickman, A., Everatt, K., Flyman, M., Henschel, P., Hinks, A.E., Kasiki, S., Loveridge, A., Macdonald, D.W., Mandisodza, R., Mgoola, W., Miller, S.M., Nazerali, S., Siege, L., Uiseb, K., Hunter, L. T.B., 2017. The performance of African protected areas for lions and their prey. Biol. Conserv. 209, 137-149. https://doi.org/10.1016/j.biocon.2017.01.011.

Macdonald, D.W., Johnson, P.J., Albrechtsen, L., Seymour, S., Dupain, J., Hall, A., Fa, J. E., 2012. Bushmeat trade in the Cross-Sanaga rivers region: evidence for the importance of protected areas. Biol. Conserv. 147, 107-114. https://doi.org/ 10.1016/j.biocon.2011.12.018.

Mackenzie, C.A., 2012. Accruing benefit or loss from a protected area: location matters. Ecol. Econ. 76, 119-129. https://doi.org/10.1016/j.ecolecon.2012.02.013.

MAE, 2005. Perfil do Distrito the Mecula Província de Niassa. Maputo.

Maru, Y., Sparrow, A., Stirzaker, R., Davies, J., 2018. Integrated agricultural research for development (IAR4D) from a theory of change perspective. Agric. Syst. 165, 310-320. https://doi.org/10.1016/j.agsy.2016.09.012.

Marzoli, A., 2007. Inventário Florestal Nacional. Maputo.

Mbanze, A.A., Batista, A.C., Tetto, A.F., Koehler, H.S., Manteiga, J.B., 2015. Influence of the meteorological conditions on forest fires occurrences in Lichinga District, Northern Mozambique. Floresta 45, 577-586. https://doi.org/10.5380/rf v45i3.33742.

Mbanze, A., Martins, M., Rivaes, R., Ribeiro-Barros, A., Ribeiro, N., 2019a. Field data on vegetation structure and effects of human use of the dambos ecosystem in Northern Mozambique. Data Brief 26, 1-8. https://doi.org/10.1016/j.gecco.2019.e00704.

Mbanze, A., Ribeiro, N., Da Silva, C., Lima, J., 2019b. An expert-based approach to assess the potential for local people engagement in nature conservation: the case study of the Niassa National Reserve in Mozambique. J. Nat. Conserv. 9-11. https://doi.org/ 10.1016/j.jnc.2019.125759 in Press.

Meyfroidt, P., Lambin, E.F., 2008. The causes of the reforestation in Vietnam. Land Use Policy 25, 182-197. https://doi.org/10.1016/j.landusepol.2007.06.001.

MICOA, 2014. Fifth National Report on Implementation of the Convention on Biological Diversity in MOZAMBIQUE. Maputo.

Moreto, W.D., 2019. Provoked poachers? Applying a situational precipitator framework to examine the nexus between human-wildlife conflict, retaliatory killings, and poaching. Crim. Justice Stud. 32, 63-80. https://doi.org/10.1080/ 1478601X.2019.1600816.

Naidu, M.T., Kumar, O.A., 2016. Tree diversity, stand structure and community composition of tropical forests in eastern Ghats of Andhra Peadesh, India. J. Asia. Biodivers. 9, 328-334. https://doi.org/10.1016/j.japb.2016.03.019.

NCP, 2015. ANNUAL REPORT 2015: Niassa Carnivore Project.

NCP, 2017. Niassa Carnivore Project Annual Report. Niassa Carnivores Project.

Peterman, W.E., Crawford, J.A., Kuhns, A.R., 2013. Using species distribution and occupancy modeling to guide survey efforts and assess species status. J. Nat. Conserv. 21, 114-121. https://doi.org/10.1016/j.jnc.2012.11.005.

Prin, T., Chamaillé, S., Grosbois, V., Fritz, H., Guerbois, C., Chardonnet, P., Cornélis, D., 2014. Understanding the mechanisms limiting the buffalo population in Niassa National Reserve, Mozambique. In: African Buffalo Symposium. IUCN Species Survival Commission, Antelope Specialist Group, African Buffalo Initiative Group. 
Reboul, C., 2009. Mode de production et systèmes de culture et d'élevage. Économie Rurale 112, 55-65. https://doi.org/10.3406/ecoru.1976.2413.

Ribeiro, N.S., Shugart, H.H., Washington-Allen, R., 2008. The effects of fire and elephants on species composition and structure of the Niassa Reserve, northern Mozambique. For. Ecol. Manage. 255, 1626-1636. https://doi.org/10.1016/j. foreco.2007.11.033.

Ribeiro, N.S., Matos, C.N., Moura, I.R., Washington-Allen, R.A., Ribeiro, A.I., 2013. Monitoring vegetation dynamics and carbon stock density in miombo woodlands. Carbon Balance Manag. 8, 1-9. https://doi.org/10.1186/1750-0680-8-11.

Ribeiro, P.F., Santos, J.L., Bugalho, M.N., Santana, J., Reino, L., Beja, P., Moreira, F., 2014. Modelling farming system dynamics in High Nature Value Farmland under policy change. Agric. Ecosyst. Environ. 183, 138-144. https://doi.org/10.1016/j. agee.2013.11.002.

Riggio, J., Jacobson, A., Dollar, L., Bauer, H., Becker, M., Dickman, A., Funston, P., Groom, R., Henschel, P., de Iongh, H., Lichtenfeld, L., Pimm, S., 2013. The size of savannah Africa: a lion's (Panthera leo) view. Biodivers. Conserv. 22, 17-35. https://doi.org/10.1007/s10531-012-0381-4.

Rogan, M.S., Lindsey, P.A., Tambling, C.J., Golabek, K.A., Chase, M.J., Collins, K., McNutt, J.W., 2017. Illegal bushmeat hunters compete with predators and threaten wild herbivore populations in a global tourism hotspot. Biol. Conserv. 210, 233-242. https://doi.org/10.1016/j.biocon.2017.04.020.

Ryan, C.M., Pritchard, R., McNicol, I., Owen, M., Fisher, J.A., Lehmann, C., 2016. Ecosystem services from southern African woodlands and their future under global change. Philos. Trans. Biol. Sci. 371, 20150312. https://doi.org/10.1098/ rstb.2015.0312.

Saura, S., Bastin, L., Battistella, L., Mandrici, A., Dubois, G., 2017. Protected areas in the world's ecoregions: how well connected are they? Ecol. Indic. 76, 144-158. https:// doi.org/10.1016/j.ecolind.2016.12.047.

Seiler, N., Robbins, M.M., 2016. Factors influencing ranging on community land and crop raiding by mountain gorillas. Anim. Conserv. 19, 176-188. https://doi.org/ 10.1111/acv.12232

Sharpe, Donald, 2015. Your chi-square test is statistically significant: now what? Practical assessment, research \& evaluation. Pract. Assess. Res. Eval. 20 (10), 1-10.

Shepherd, C., Magnus, N., 2004. Nowhere to Hide: The Trade in Sumatran Tiger, a Traffec Southeast Asia Report. https://doi.org/10.5406/jsporthistory.44.3.0477.

Smith, H.E., Hudson, M.D., Schreckenberg, K., 2017. Livelihood diversification: the role of charcoal production in southern Malawi. Energy Sustain. Dev. 36, 22-36. https:// doi.org/10.1016/j.esd.2016.10.001.
Snyman, S., Bricker, K.S., 2016. Living on the edge: benefit-sharing from protected area tourism. J. Sustain. Tour. 24, 1480-1481. https://doi.org/10.1080/ 09669582.2016.1212528.

Sraïr, M.T., Ghabiyel, Y., 2017. Coping with the work constraints in crop-livestock farming systems. Ann. Agric. Sci. 62, 23-32. https://doi.org/10.1016/j. aoas.2017.01.001.

SRN, 2008. Plano de Maneio da Reserva Nacional do Niassa (Draft Final) 2007 - 2012. Maputo.

Staal, S.J., Baltenweck, I., Waithaka, M.M., Njoroge, L., 2002. Location and uptake: integrated household and GIS analysis of technology adoption and land use, with application to smallholder dairy farms in Kenya. Agric. Econ. 27, 295-315.

Struhsaker, T.T., Struhsaker, P.J., Siex, K.S., 2005. Conserving Africa's rain forests: problems in protected areas and possible solutions. Biol. Conserv. 123, 45-54. https://doi.org/10.1016/j.biocon.2004.10.007.

Tufa, B., Girma, Z., Mengesha, G., 2018. Human-large wild mammals conflict in DheraDilfaqar Block of Arsi Mountains National Park, South Eastern Ethiopia. Hum. Dimens. Wildl. 23, 474-481. https://doi.org/10.1080/10871209.2018.1464616.

Twongyirwe, R., Bithell, M., Richards, K.S., 2018. Revisiting the drivers of deforestation in the tropics: insights from local and key informant perceptions in western Uganda. J. Rural Stud. 63, 105-119. https://doi.org/10.1016/j.jrurstud.2018.08.013.

UNEP, CITES, IUCN, TRAFFIC, 2013. Elephants in the Dust - The African Elephant Crisis. van de Steeg, J.A., Verburg, P.H., Baltenweck, I., Staal, S.J., 2010. Characterization of the spatial distribution of farming systems in the Kenyan Highlands. Appl. Geogr. 30, 239-253. https://doi.org/10.1016/j.apgeog.2009.05.005.

Vollmer, F., Zorrilla-Miras, P., Baumert, S., Luz, A.C., Woollen, E., Grundy, I., Artur, L., Ribeiro, N., Mahamane, M., Patenaude, G., 2017. Charcoal income as a means to a valuable end: scope and limitations of income from rural charcoal production to alleviate acute multidimensional poverty in Mabalane district, southern Mozambique. World Dev. Perspect. 7-8, 43-60. https://doi.org/10.1016/j. wdp.2017.11.005.

Woollen, E., Ryan, C., Grundy, I., Baumert, S., Vollmer, F., Fernando, J., Luz, A., Ribeiro, N., Fisher, J., Lisboa, S.N., 2016. Charcoal production in the Mopane woodlands of Mozambique: what are the tradeoffs with other ecosystem services? Philos. Trans. R. Soc. B-Biol. Sci. 1-14. https://doi.org/10.1098/rstb.2015.0315.

WWF, 2012. Miombo Eco-Region "Home of the Zambezi" Conservation Strategy: 2011$20202011-2020$.

Yang, L., Liu, M., Min, Q., Li, W., 2018. Specialization or diversification? The situation and transition of households' livelihood in agricultural heritage systems. Int. J. Agric. Sustain. 16, 455-471. https://doi.org/10.1080/14735903.2018.1537669. 